Supplementary material for the paper:

\title{
Design and Synthesis of New Macrocyclic Cyclophanes Using 1,3-Dioxane Units as Bridges: A Molecular "Rocking Chair".
}

by

Mirela Balog, Ion Grosu, Gérard Plé, Yvan Ramondenc, Eric Condamine and Richard A. Varga

\section{Table of contents:}

1. General experimental data 2

2. Compound 2a: Structural formula, ${ }^{1} \mathrm{H},{ }^{13} \mathrm{C}$ and EI-MS spectra 3

3. Compound 2b: Structural formula and MALDI-TOF spectrum 5

4. Compound 2c: Structural formula and MALDI-TOFspectrum 6

5. Compound 3a: Structural formula, ${ }^{1} \mathrm{H},{ }^{13} \mathrm{C}$ and EI-MS spectra 7

6. Compound 3b: Structural formula, ${ }^{1} \mathrm{H},{ }^{13} \mathrm{C}$ and MALDI-TOF spectra 9

7. Compound 3c: Structural formula, ${ }^{1} \mathrm{H},{ }^{13} \mathrm{C}$ and MALDI-TOF spectra 11

8. Compound 4a: Structural formula, ${ }^{1} \mathrm{H},{ }^{13} \mathrm{C}$ and EI spectra 13

9. Compound 4b: Structural formula, ${ }^{1} \mathrm{H},{ }^{13} \mathrm{C}$ and MALDI-TOF spectra 16

10. Compound 4c: Structural formula, ${ }^{1} \mathrm{H},{ }^{13} \mathrm{C}$ and MALDI-TOF spectra 18

$\begin{array}{ll}\text { 11. NMR and X-ray structures data } & 20\end{array}$

Table 1. Reference dihedral angles for establishing the rotamers of $\mathrm{C}$ aromatic ring, determined from the molecular structure of compounds $\mathbf{2 a}, \mathbf{3 a}$ and $\mathbf{4 a}$

Table 2. Selected ${ }^{1} \mathrm{H} \mathrm{NMR}$ data $\left(\mathrm{CDCl}_{3}, \delta\right.$, ppm) for compounds $\boldsymbol{3}_{\mathrm{a}-\mathrm{c}}$ and $\mathbf{4}_{\mathrm{a}-\mathrm{c} \cdot}$. 20

Low temperature COSY spectrum of compound 2a. 21

Low temperature NOESY spectrum of compound 2a. 22

Low temperature ROESY spectrum (fragment) of compound 2a. 23

Table 3. Crystal data and structure refinement for compounds

2a, 3a and 4a. 24

$\begin{array}{ll}\text { References } & 26\end{array}$ 


\section{General experimental data}

Routine NMR spectra $\left[{ }^{1} \mathrm{H}(300.13 \mathrm{MHz}),{ }^{13} \mathrm{C}(75.47 \mathrm{MHz})\right]$ were recorded at room temperature, in $\mathrm{CDCl}_{3}$. Variable temperature NMR spectra and low temperature ROESY (with TOCSY suppression experiments), ${ }^{1} \mathrm{NOESY}$ and COSY spectra were recorded on a $500 \mathrm{MHz}$ spectrometer in $\left[\mathrm{D}_{8}\right]$-THF or $\mathrm{CD}_{2} \mathrm{Cl}_{2}$. Melting points are uncorrected. Microanalyses $(\mathrm{C}, \mathrm{H})$ agreed (inside \pm 0.2 $\%)$ with calculated data.

X-ray Crystallography. Data (compounds 2a, 3a-and 4a) were collected using graphitemonochromated Mo K radiation ( = $0.71073 \AA$ ). For this purpose the crystals were attached with silicon grease to a cryoloop. Data was collected at room temperature (297 K). The structures were refined with anisotropic thermal parameters. The hydrogen atoms were refined with a riding model and a mutual isotropic thermal parameter. For structure solving and refinement a software package SHELX-97 was used. ${ }^{2}$ The drawings were created with Ortep ${ }^{3}$ and Diamond programs. ${ }^{4}$ Crystallographic data (excluding structure factors) for the structures reported in this paper have been deposited with the Cambridge Crystallographic Data Centre as supplementary publication no. CCDC-213736 - 213738. Copies of the data can be obtained free of charge on application to CCDC, 12 Union Road, Cambridge CB2 1EZ, UK [Fax: int. code + 44(1223)336-033; E-mail: deposit@ccdc.cam.ac.uk].

General procedure for the preparation of [7.7]cyclophanes (2a-4a), [7.7.7.7]cyclophanes (3b, 4b) and [7.7.7.7.7.7]cyclophanes (3c, $4 \mathbf{c})$ :

A solution of phthaloyl dichloride (ortho, meta or para) $(0.33 \mathrm{mmol})$ in dry THF (20 ml) was added with a high precision push-syringe over a period of $12 \mathrm{~h}$ to a well-stirred solution of diol 1 (0.27 mmol) in dry $\mathrm{CH}_{3} \mathrm{CN}(60 \mathrm{ml})$ and dry THF $(15 \mathrm{ml})$ containing $\mathrm{N}, \mathrm{N}$ '-dimethyl-4aminopyridine (DMAP, $0.40 \mathrm{mmol}$ ) and the mixture was stirred at room temperature and the reaction was monitored by TLC. Solvents were evaporated in vacuo, the residue was triturated with ether $(100 \mathrm{ml})$ and the ether extract was evaporated in vacuo. The residue was chromatographed on silica gel to afford the target macrocycle cyclophanes. 
2. Compound 2a: Structural formula, ${ }^{1} \mathrm{H},{ }^{13} \mathrm{C}$ and EI-MS spectra.

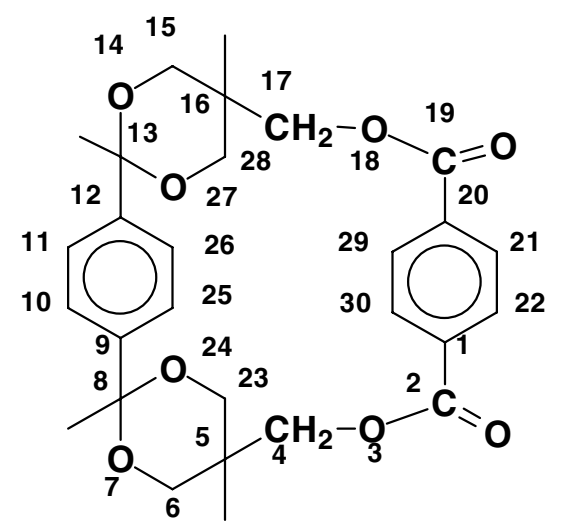

$2 a$

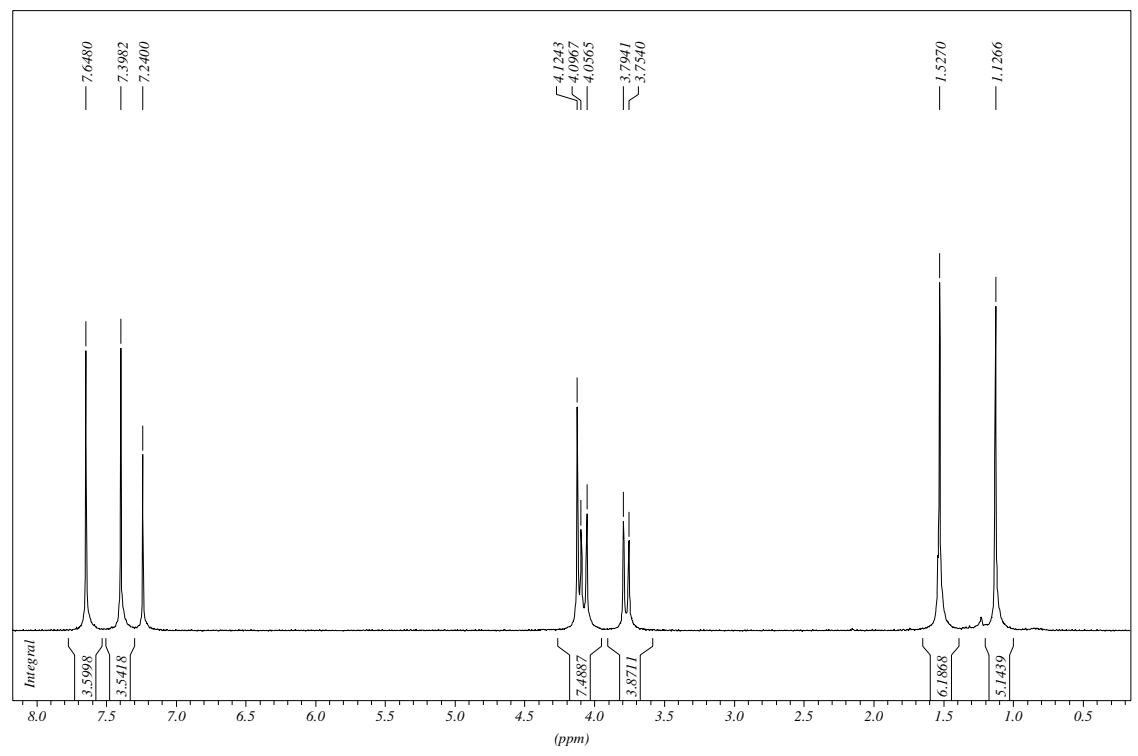

${ }^{1} \mathrm{H}-\mathrm{NMR}$ spectrum of $\mathbf{2 a}$

${ }^{13} \mathrm{C}-\mathrm{NMR}$ spectrum of $\mathbf{2 a}$ 


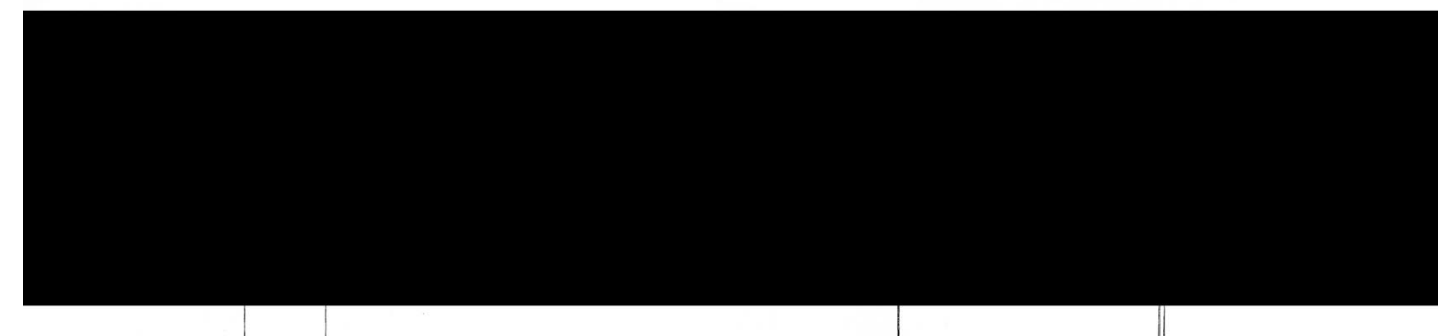

EI-MS spectrum of $\mathbf{2 a}$ 
3. Compound 2b: Structural formula, MALDI-TOF spectrum.

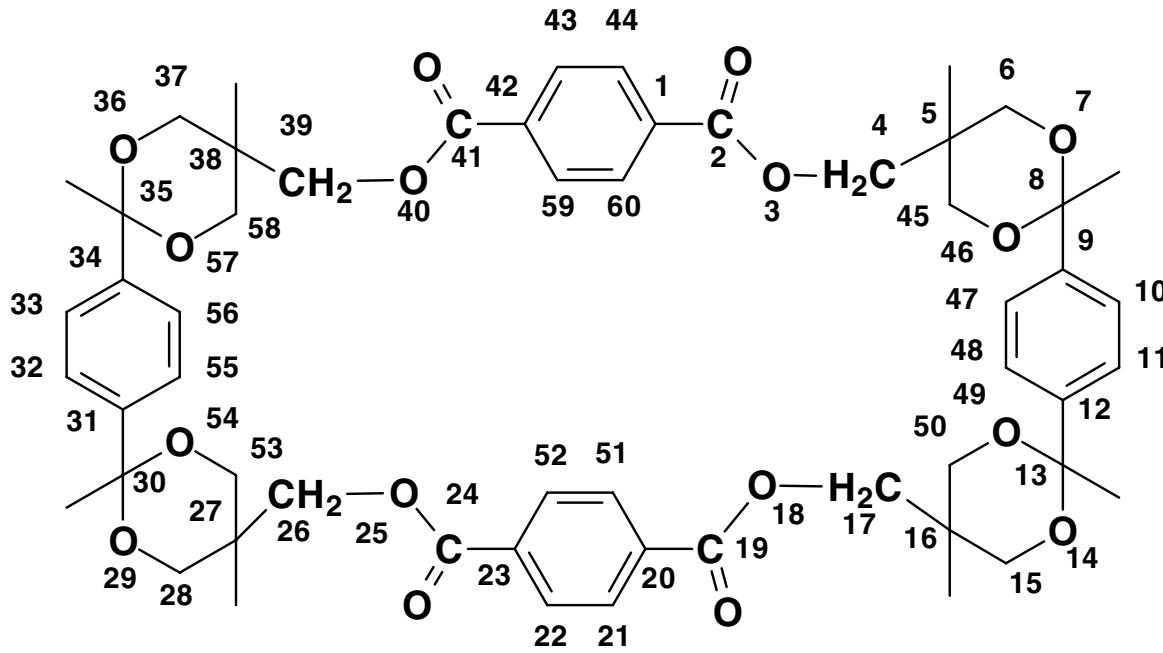

2b

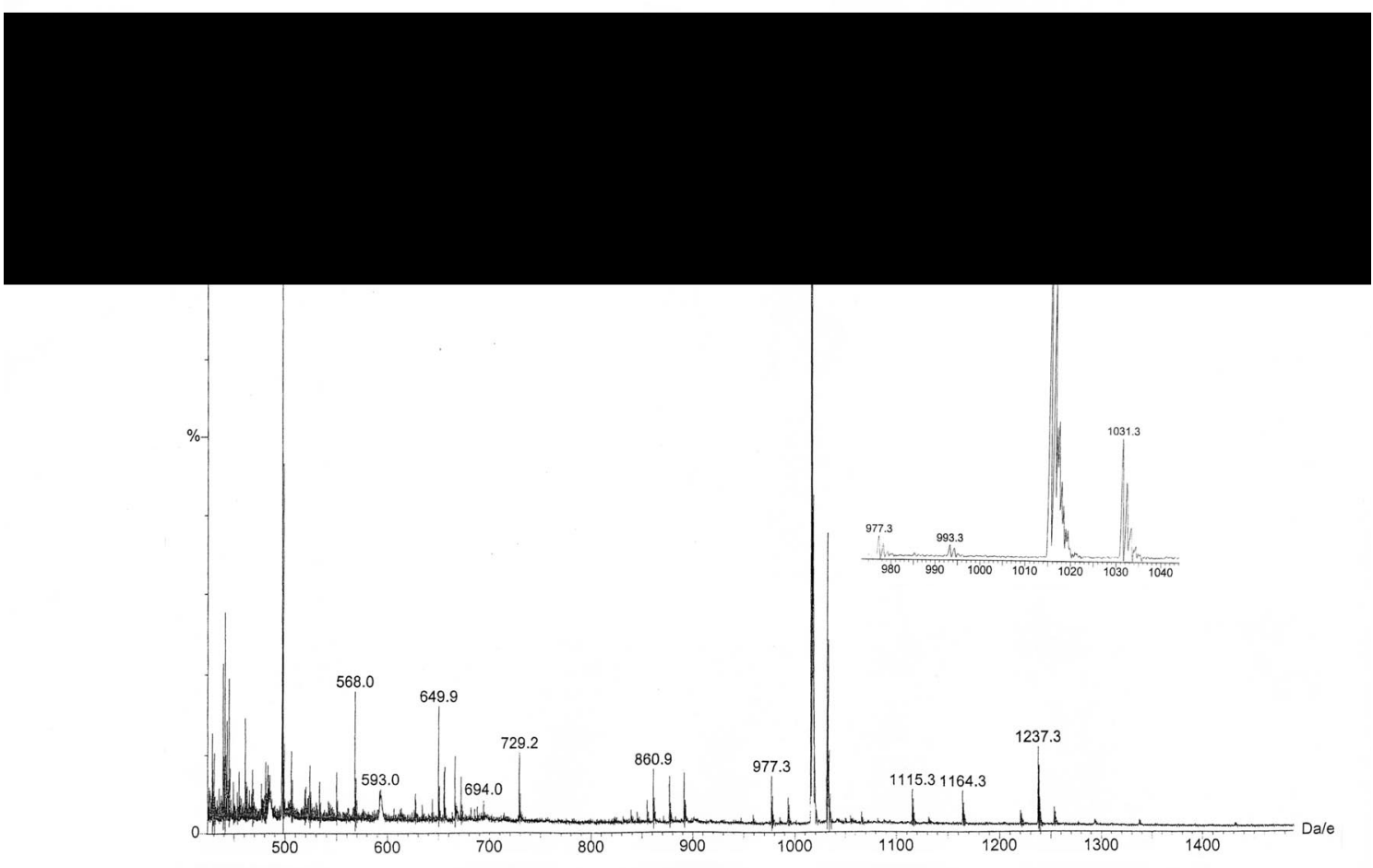

MALDI-TOF spectrum of $\mathbf{2 b}$ 
4. Compound 2c: Structural formula, MALDI-TOF spectrum.

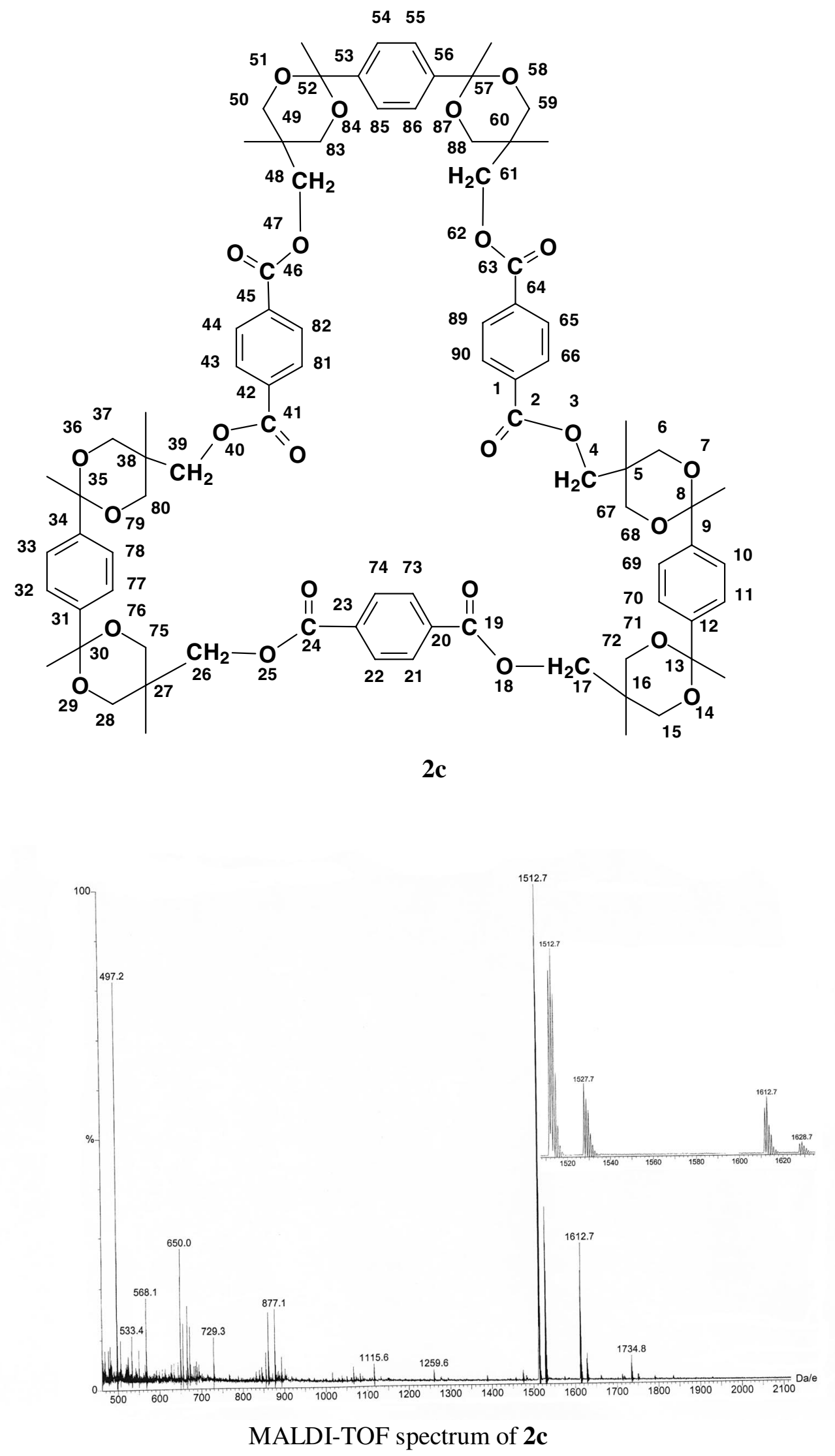


5. Compound 3a: Structural formula, ${ }^{1} \mathrm{H},{ }^{13} \mathrm{C}$ and EI-MS spectra.

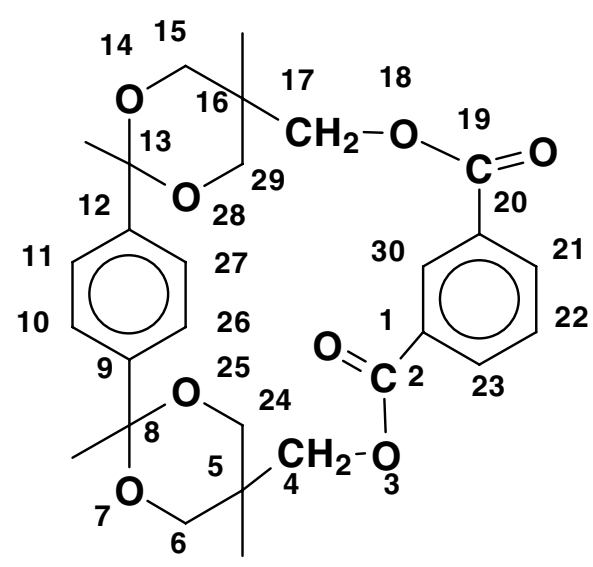

$3 a$

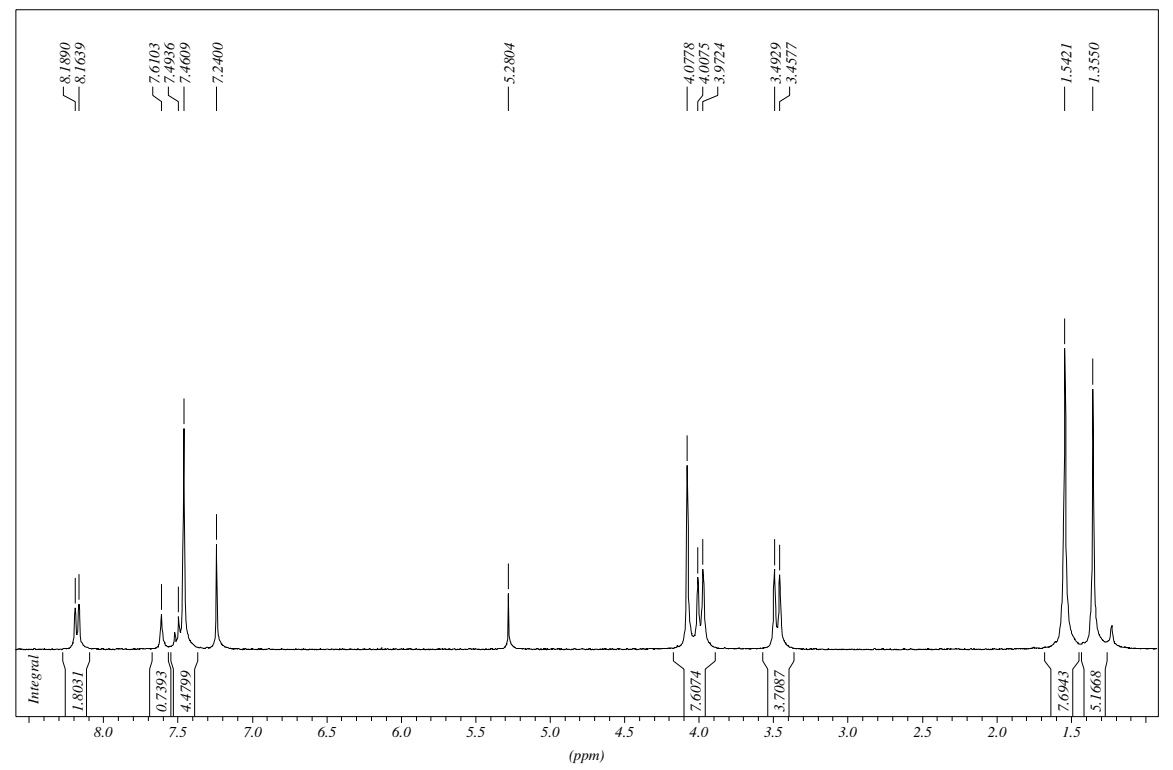

${ }^{1} \mathrm{H}$ NMR spectrum of $\mathbf{3 a}$. 


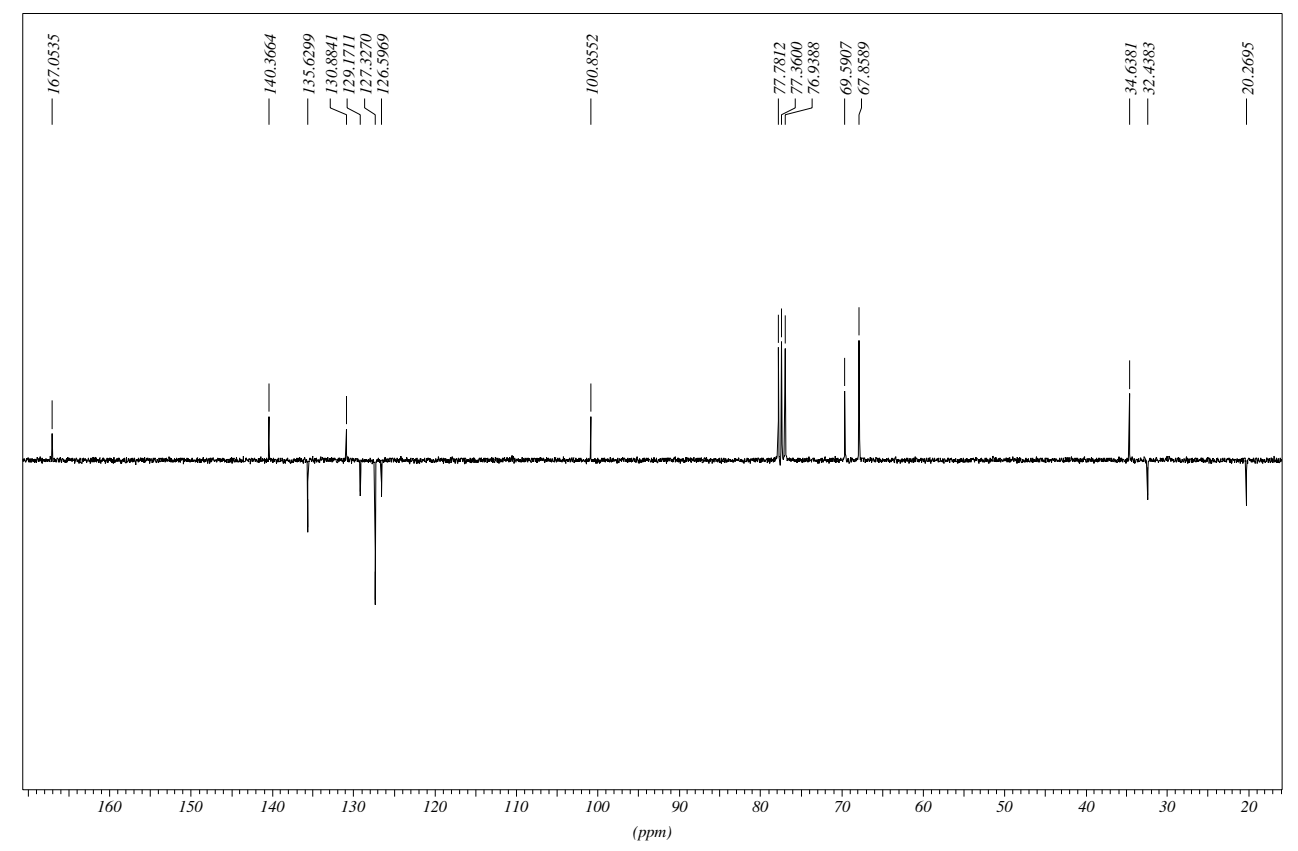

${ }^{13} \mathrm{C}$ NMR spectrum of $\mathbf{3 a}$.

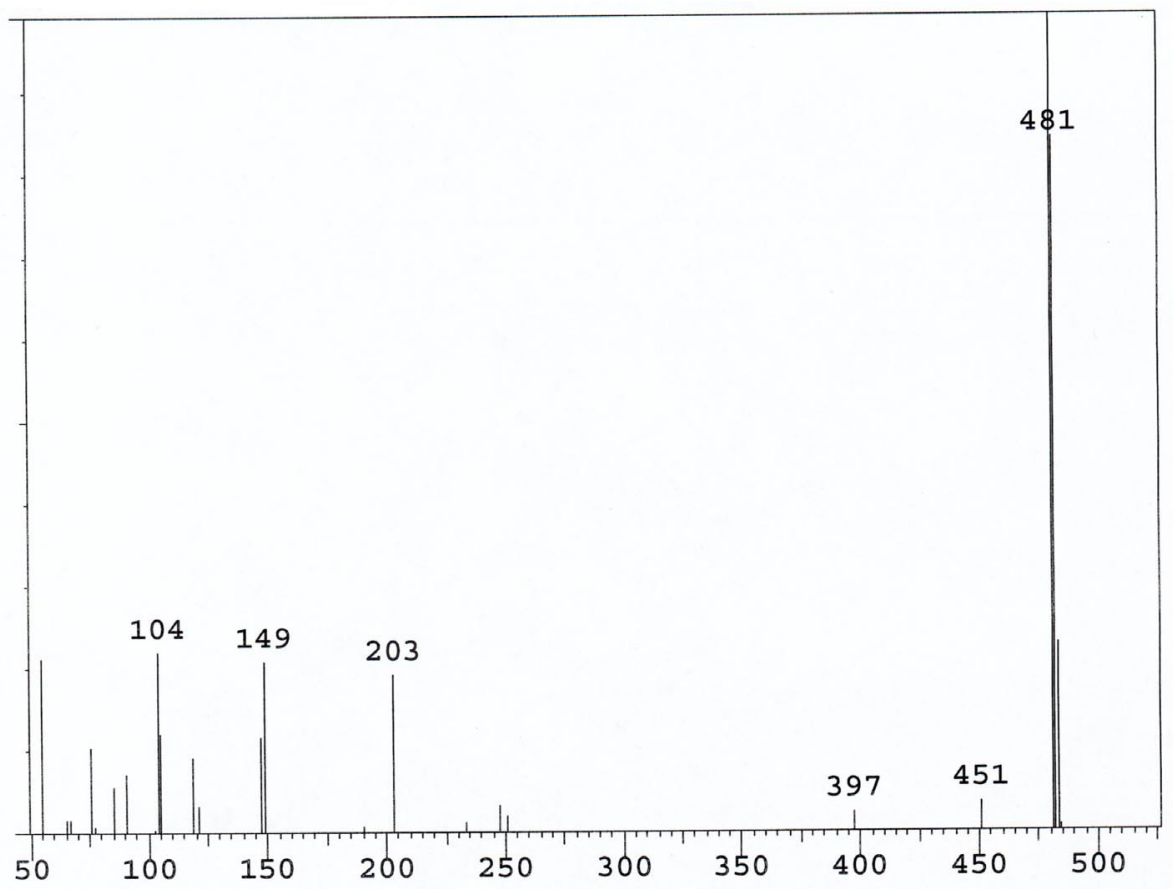

EI-MS spectrum of $\mathbf{3 a}$ 
6. Compound 3b: Structural formula, ${ }^{1} \mathrm{H},{ }^{13} \mathrm{C}$ and MALDI-TOF spectra.
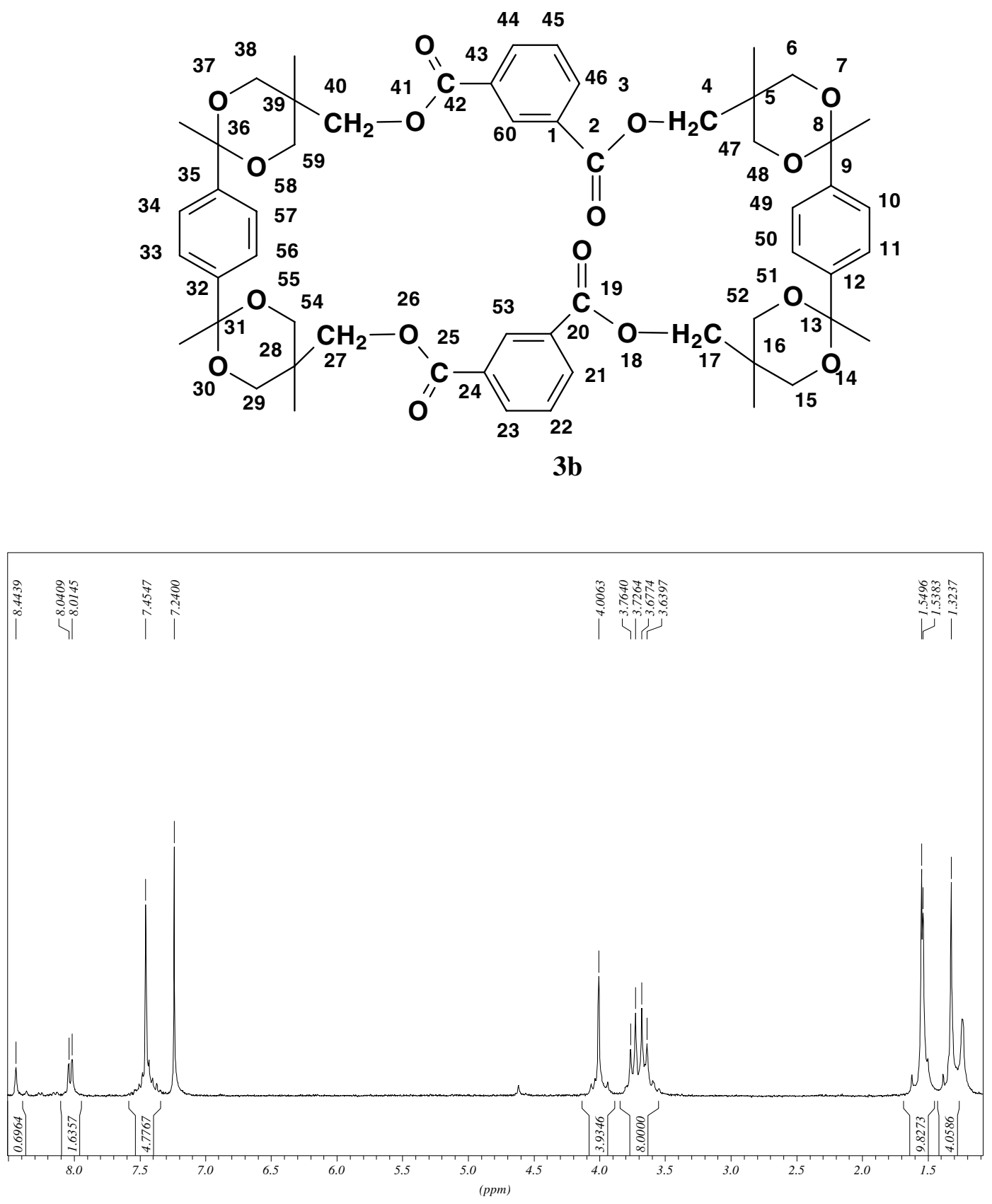

${ }^{1} \mathrm{H}$ NMR spectrum of $\mathbf{3 b}$. 

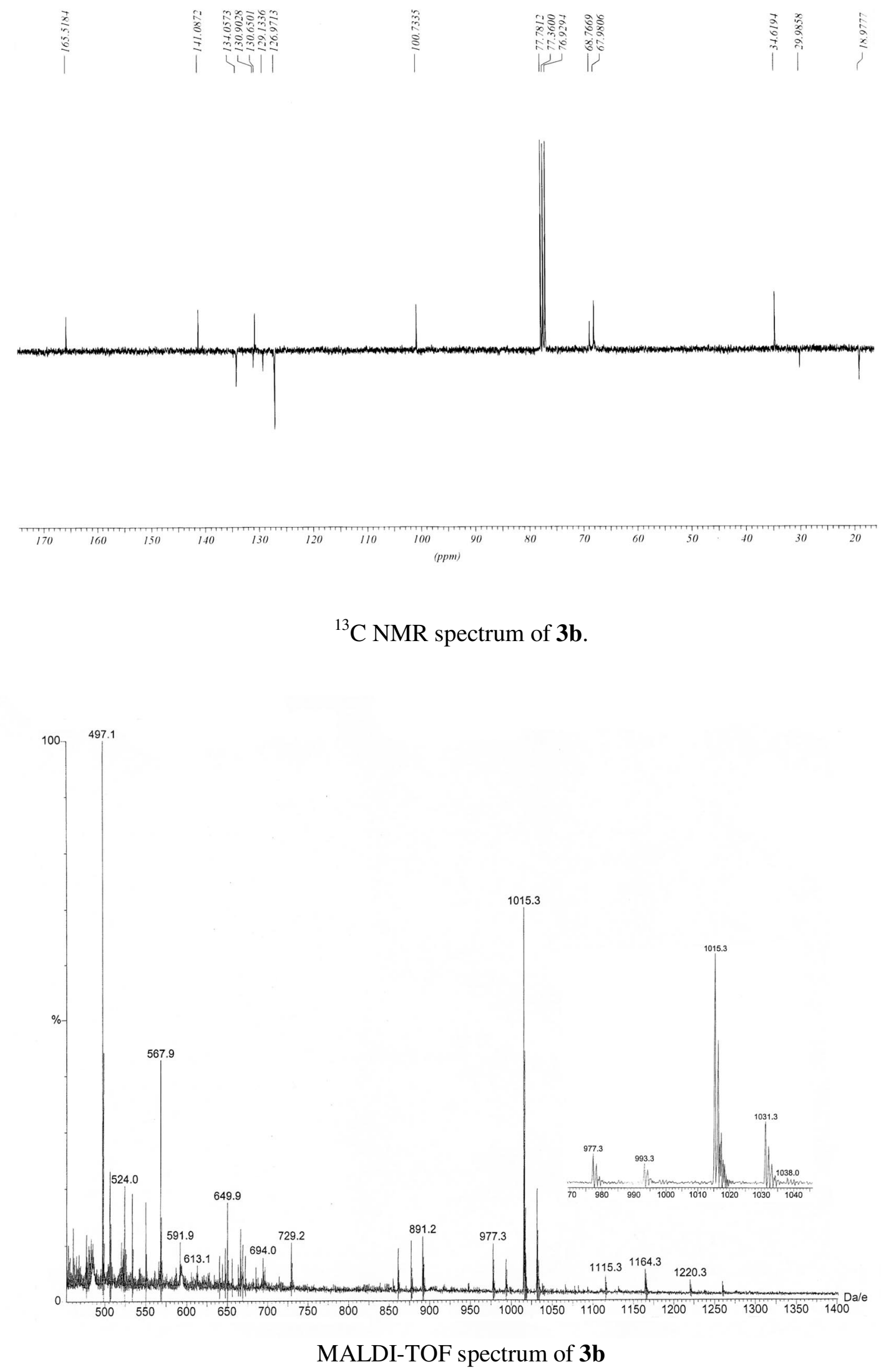
7. Compound 3c: Structural formula, ${ }^{1} \mathrm{H},{ }^{13} \mathrm{C}$ and MALDI-TOF spectra.
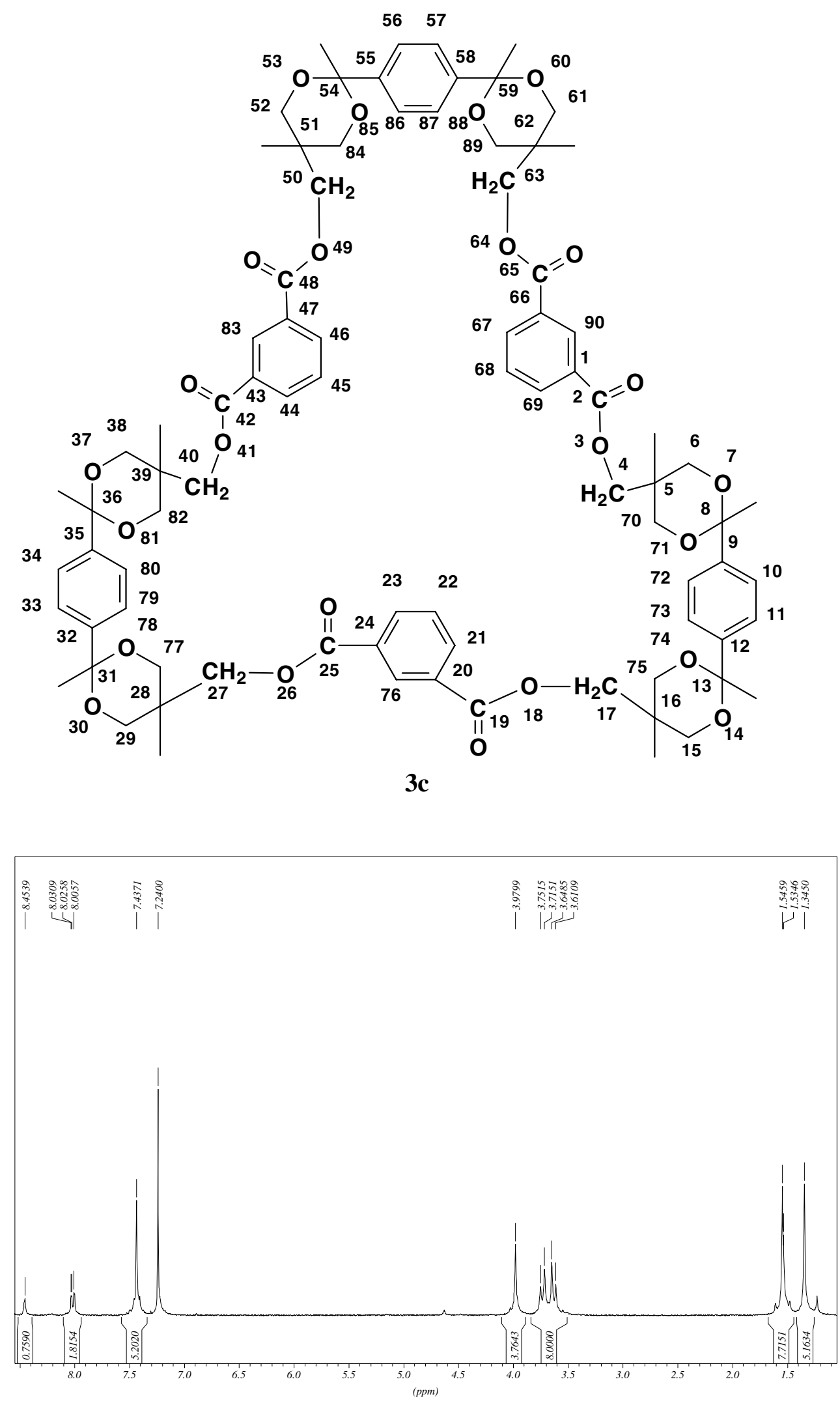

${ }^{1} \mathrm{H}$ NMR spectrum of $\mathbf{3 c}$ 


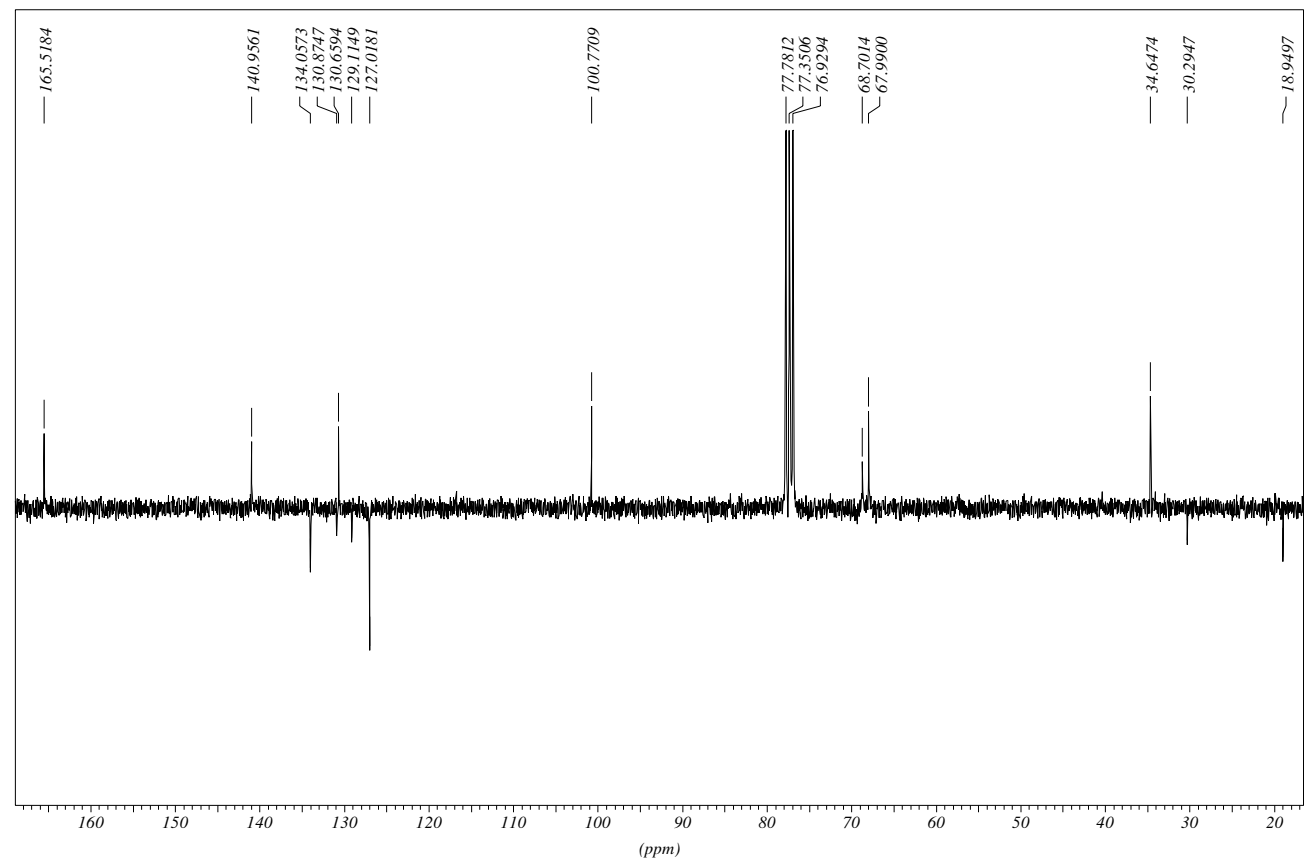

${ }^{13} \mathrm{C}$ NMR spectrum of $\mathbf{3 c}$

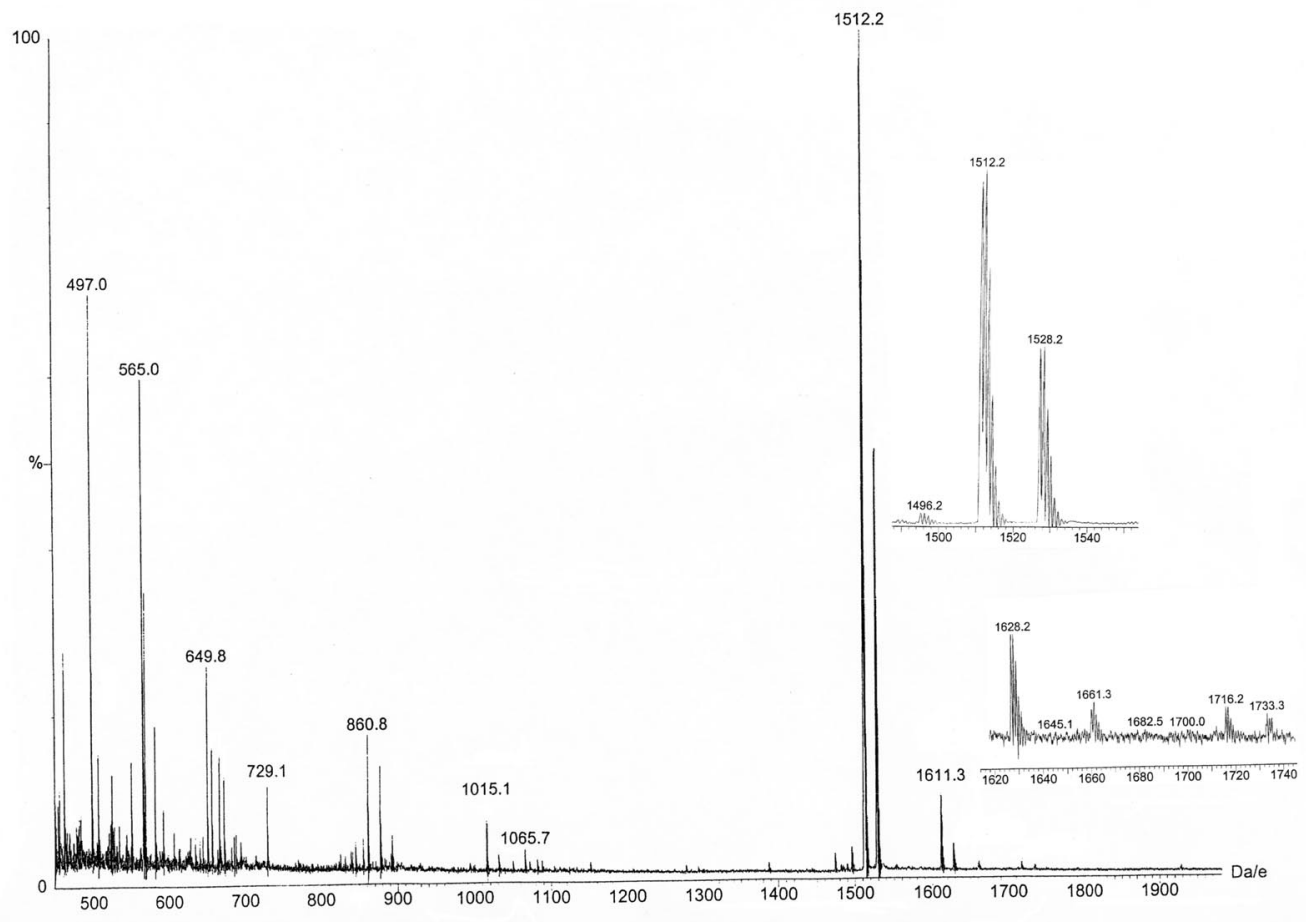

MALDI-TOF spectrum of $\mathbf{3 c}$. 
8. Compound 4a: Structural formula, ${ }^{1} \mathrm{H},{ }^{13} \mathrm{C}$ and EI-MS spectra.

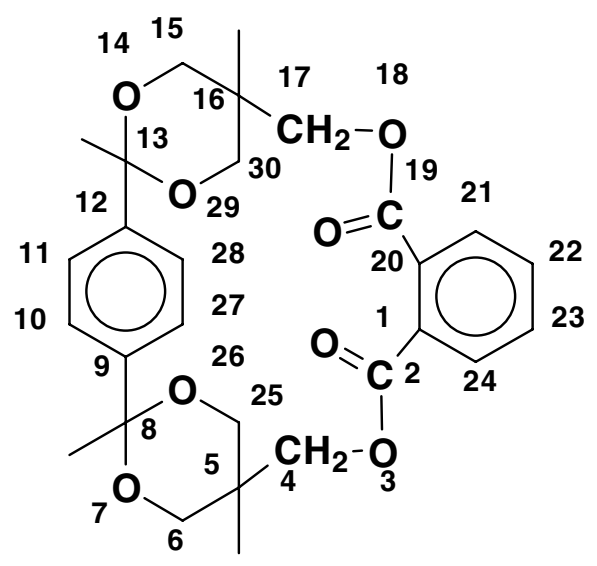

$4 a$

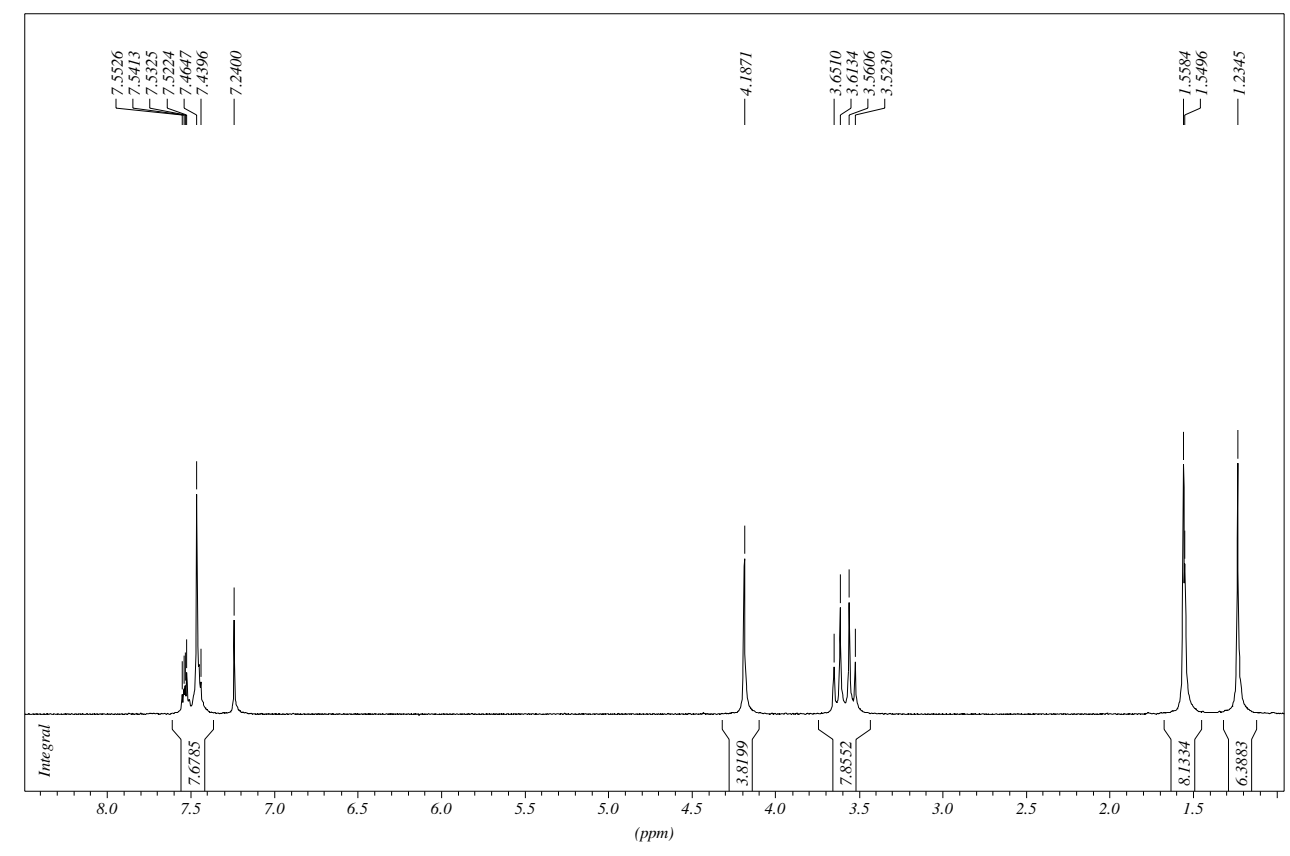

${ }^{1} \mathrm{H}-\mathrm{NMR}$ spectrum of $\mathbf{4 a}$ 


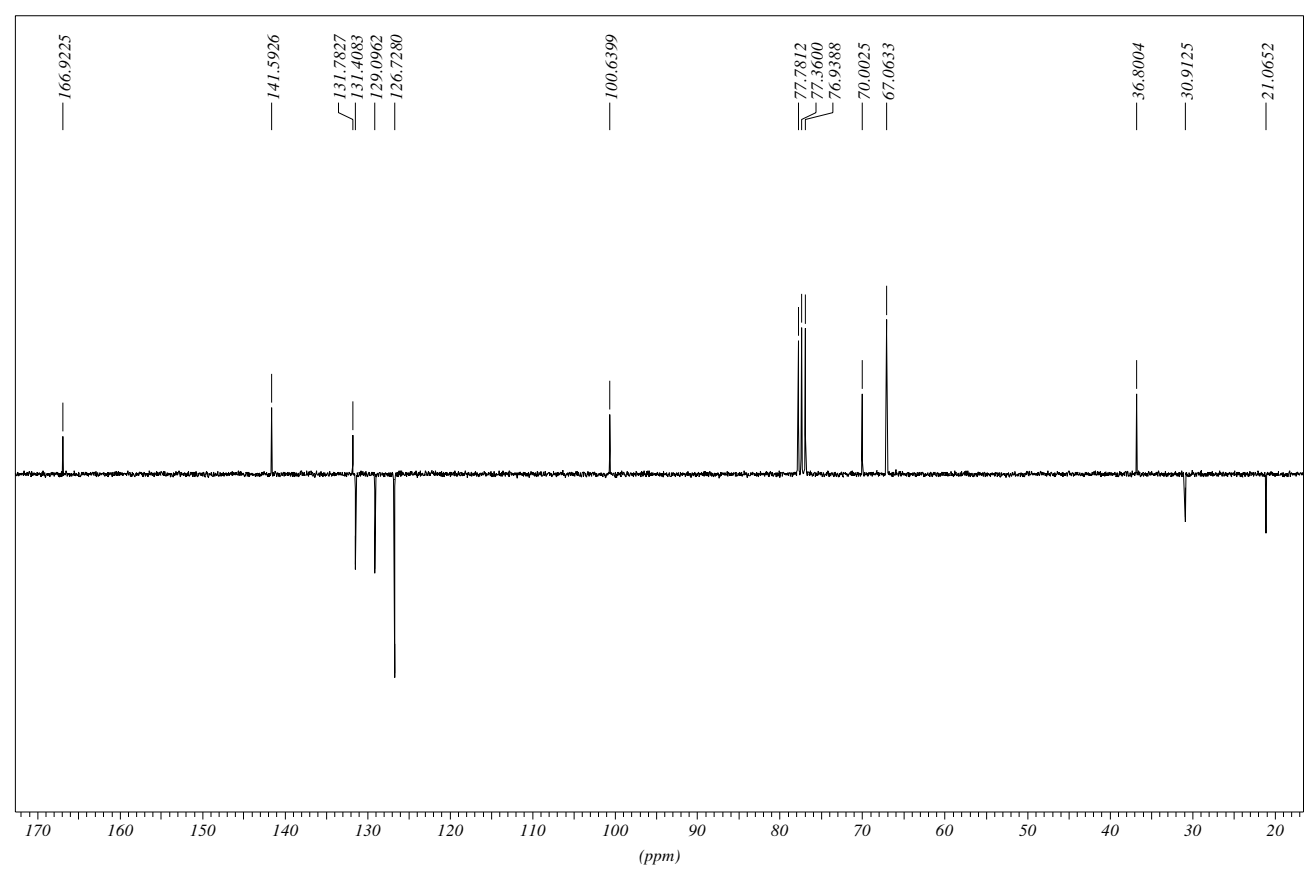

${ }^{13} \mathrm{C}-\mathrm{NMR}$ spectrum of $\mathbf{4 a}$

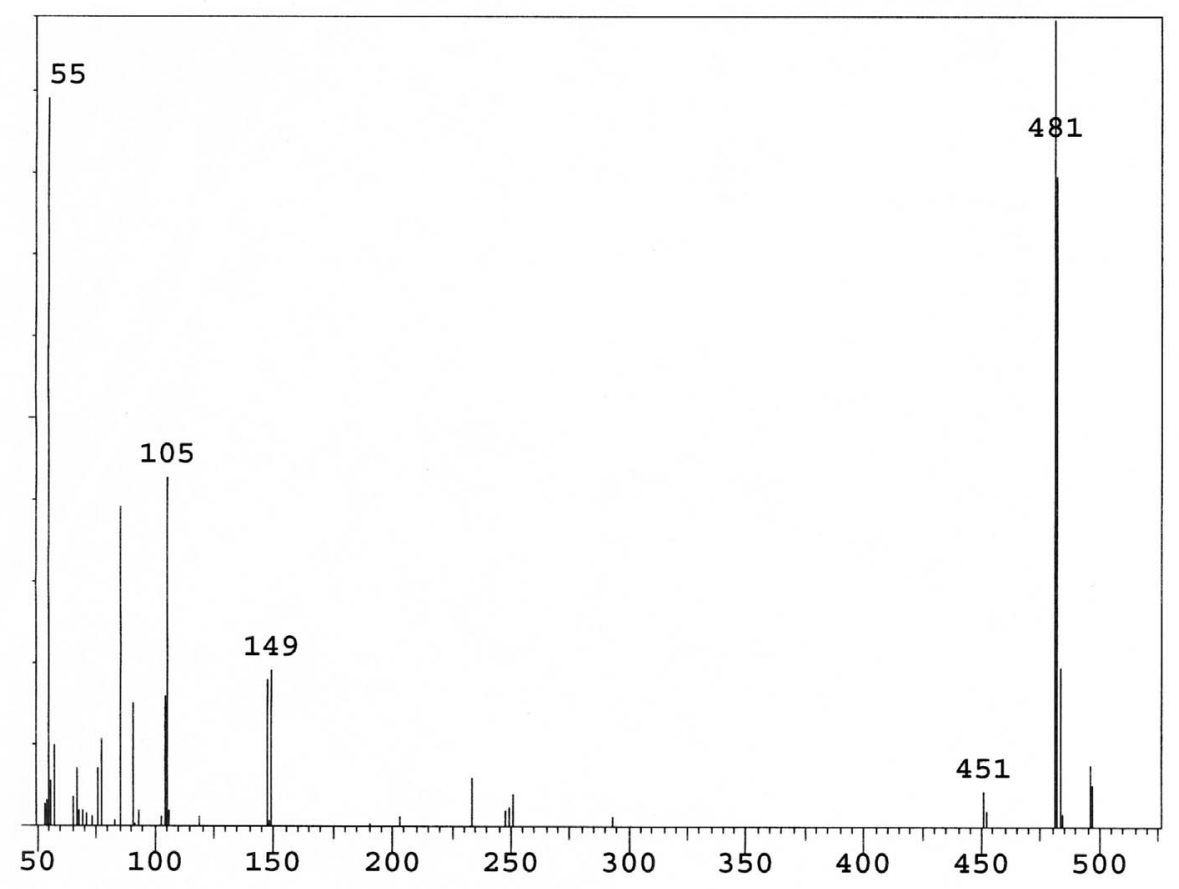

EI-MS spectrum of $\mathbf{4 a}$. 


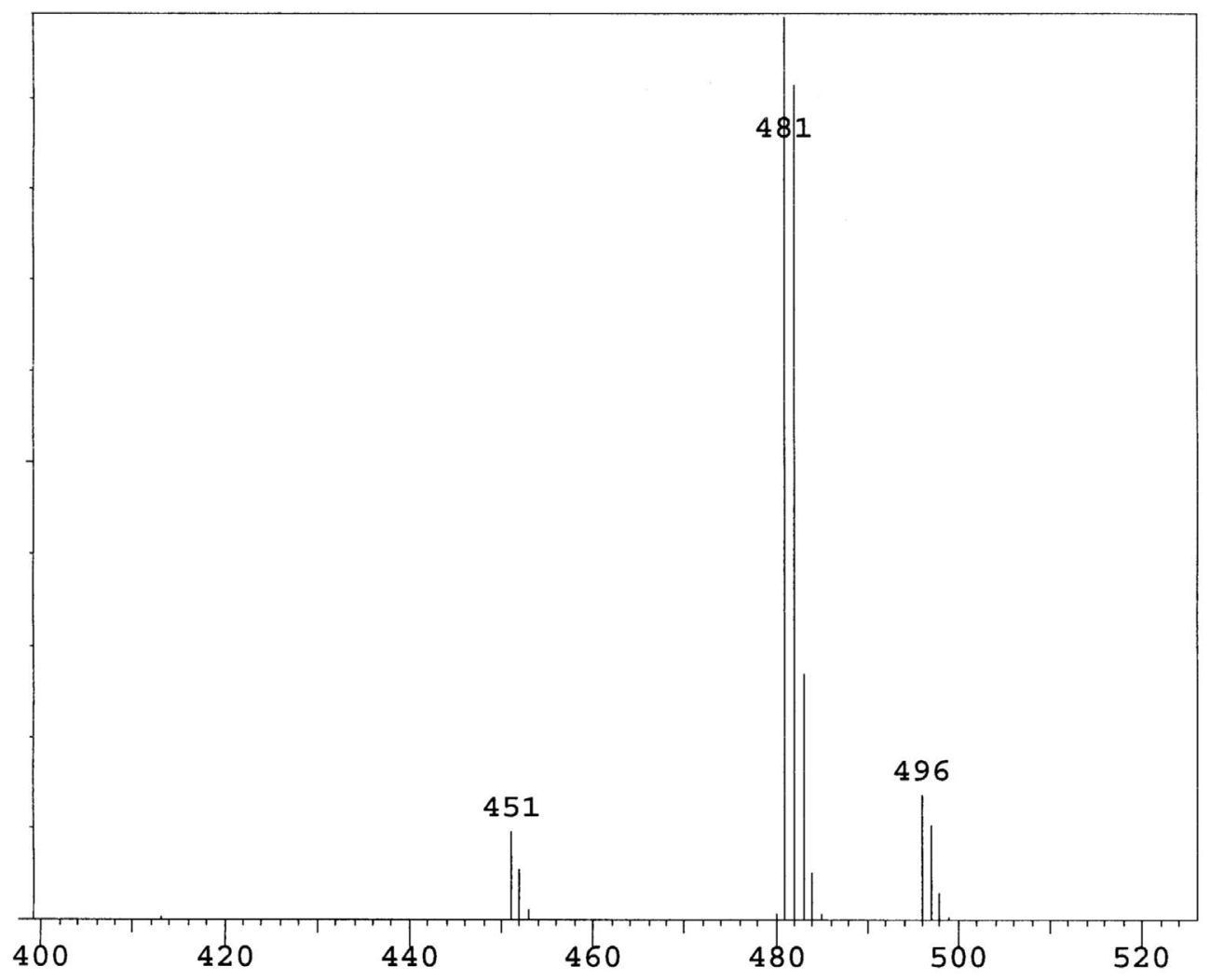

EI-MS spectrum of $\mathbf{4 a}$ (fragment). 
9. Compound 4b: Structural formula, ${ }^{1} \mathrm{H},{ }^{13} \mathrm{C}$ and MALDI-TOF spectra.
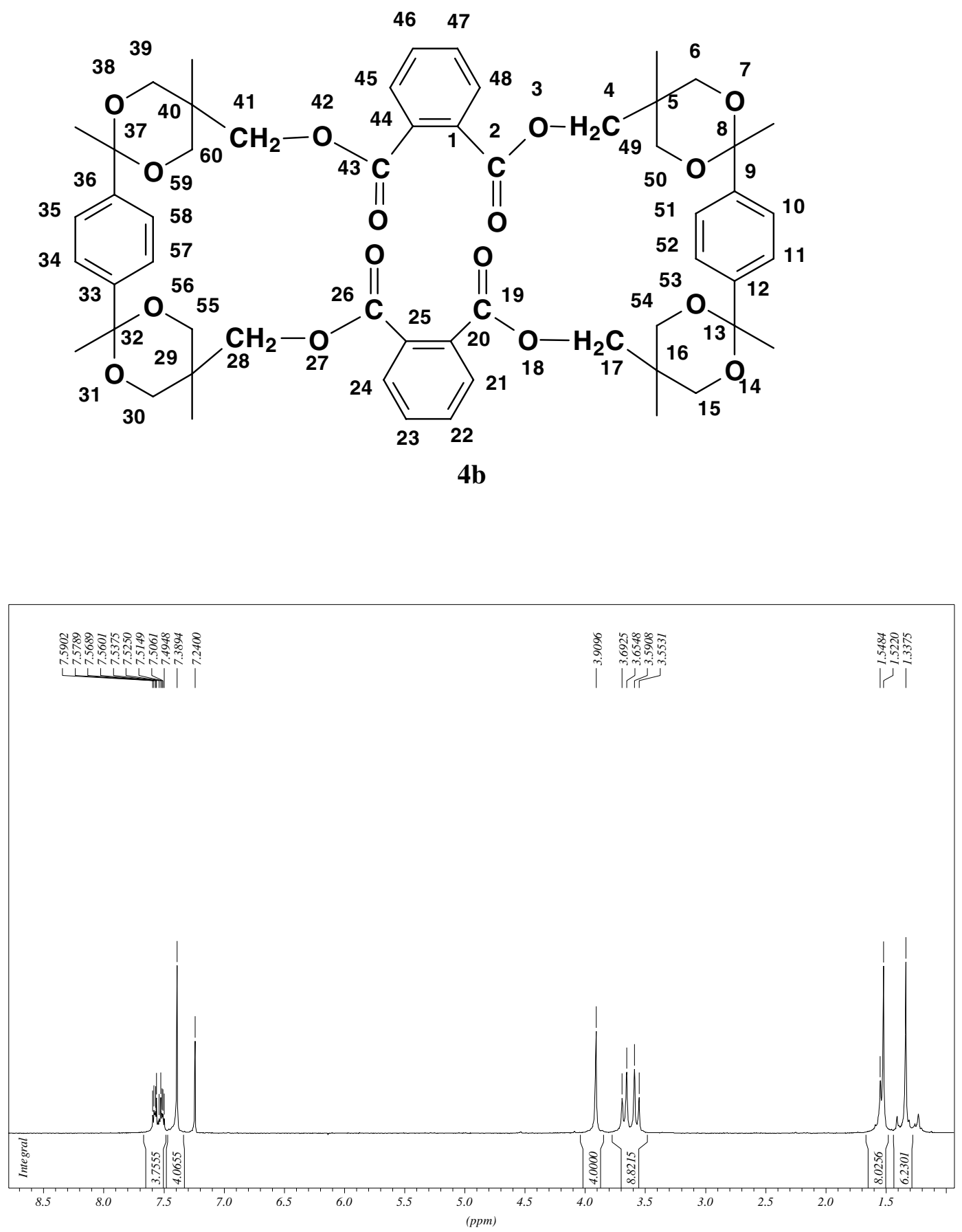

${ }^{1} \mathrm{H}$ NMR spectrum of $\mathbf{4 b}$ 


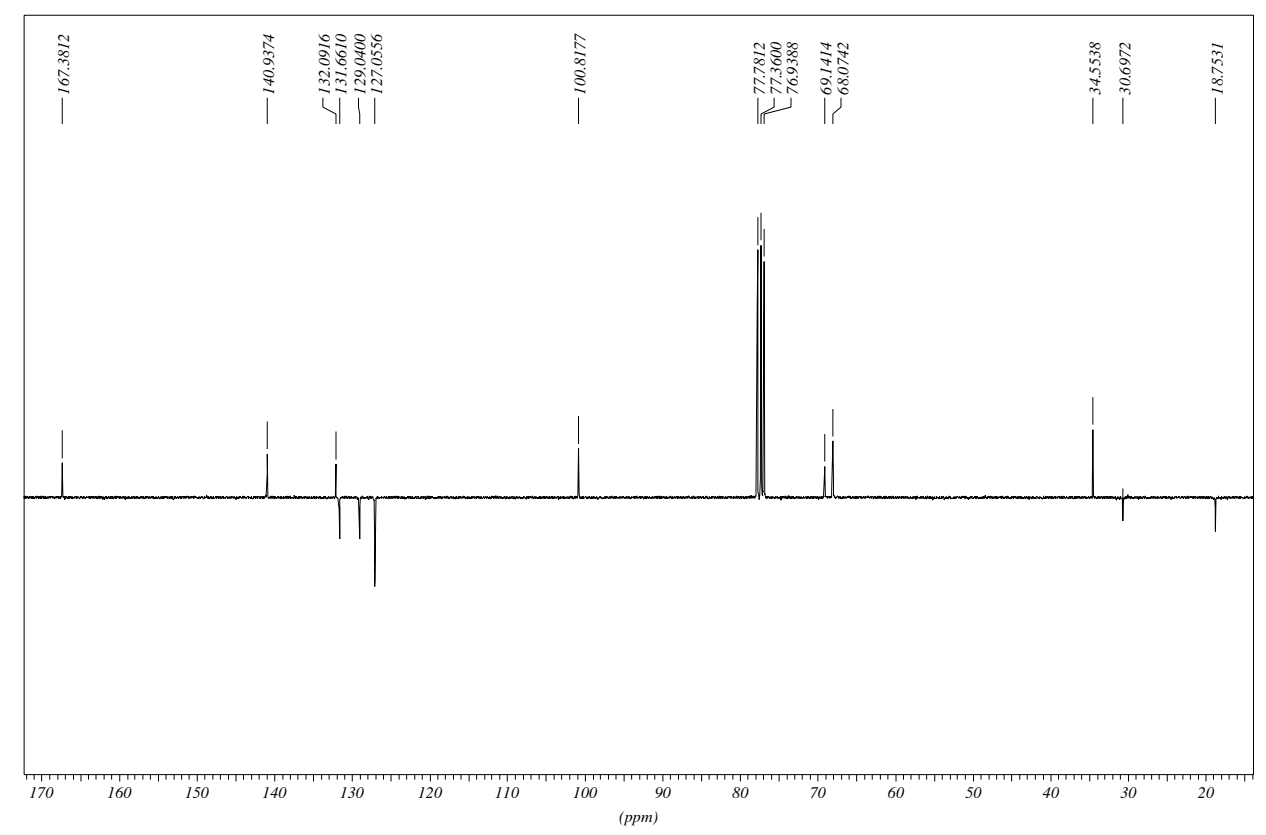

${ }^{13} \mathrm{C}$ NMR spectrum of $\mathbf{4 b}$

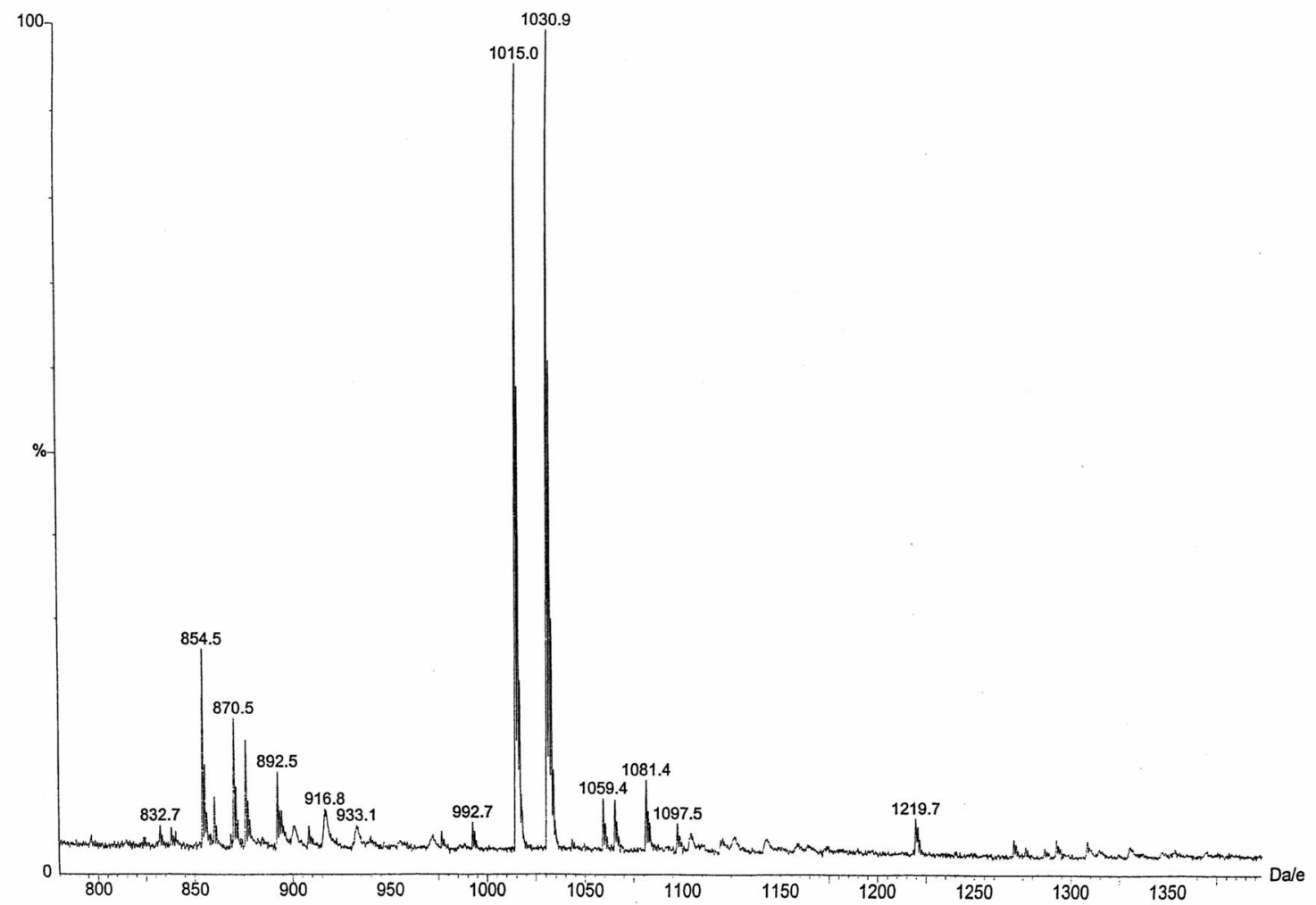

\section{MALDI-TOF spectrum of $\mathbf{4 b}$}


10. Compound 4c: Structural formula, ${ }^{1} \mathrm{H},{ }^{13} \mathrm{C}$ and MALDI-TOF spectra.
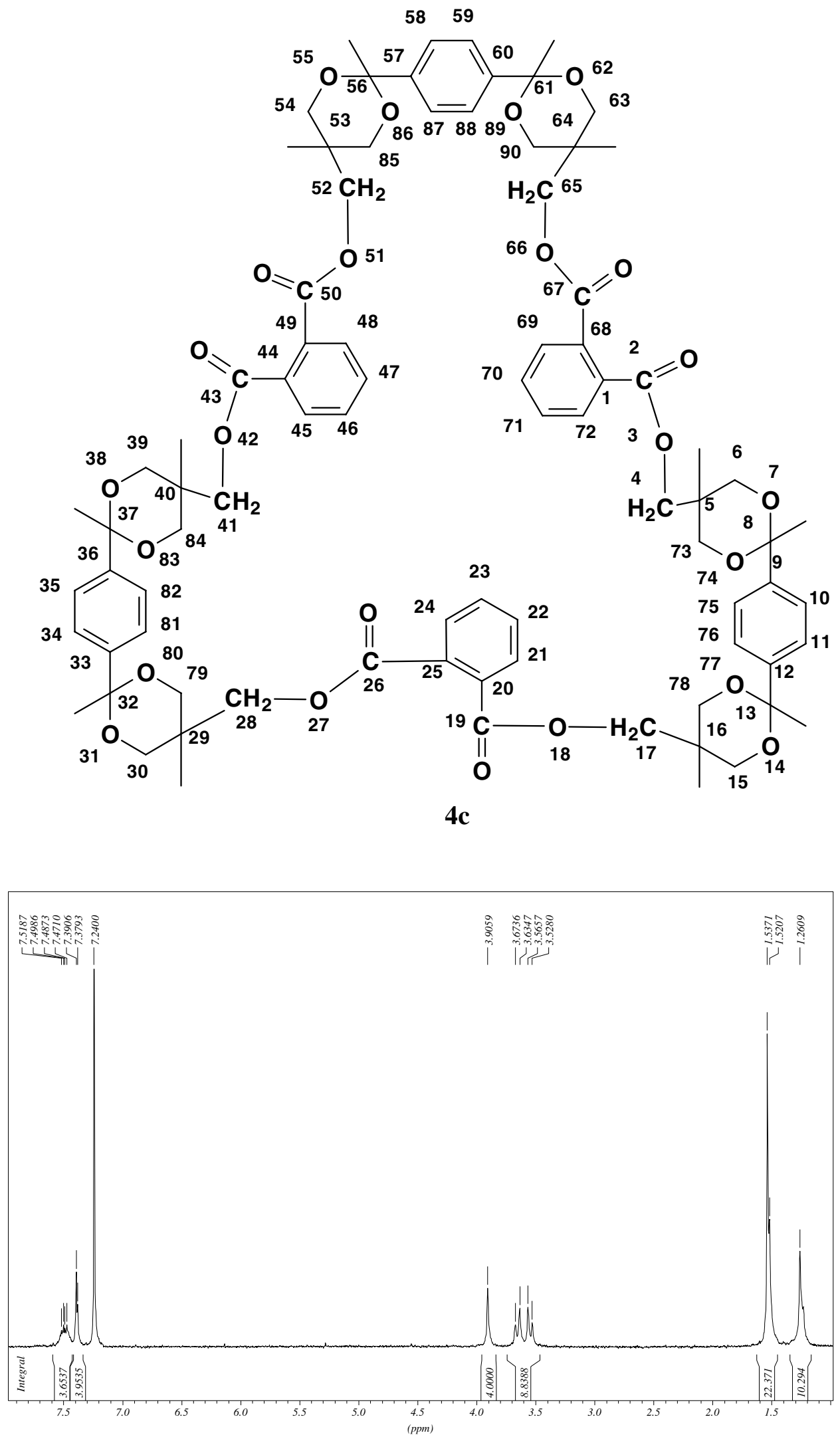

${ }^{1} \mathrm{H}$ NMR spectrum of $4 \mathrm{c}$ 


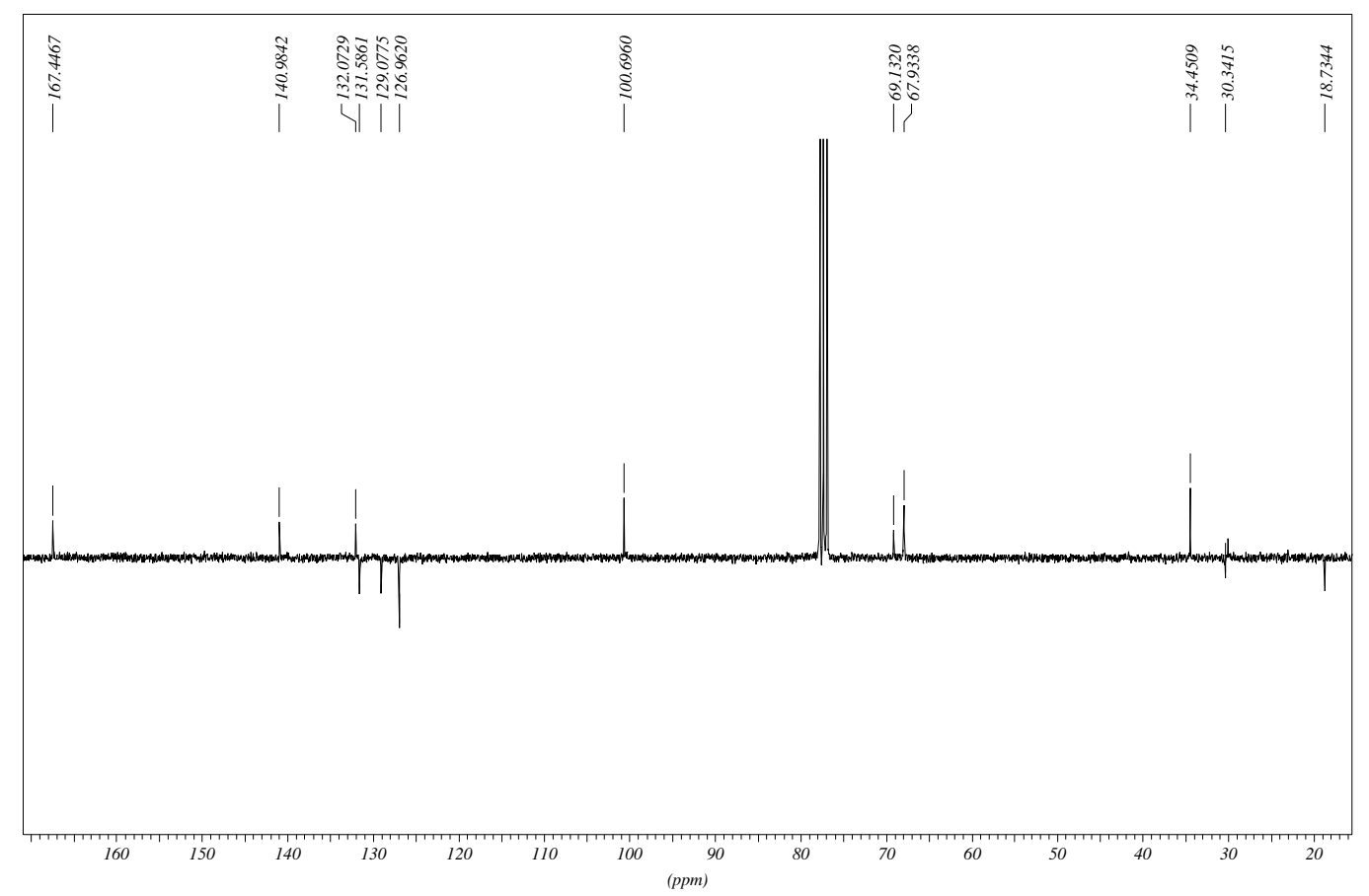

${ }^{13} \mathrm{C}$ NMR spectrum of $\mathbf{4 c}$

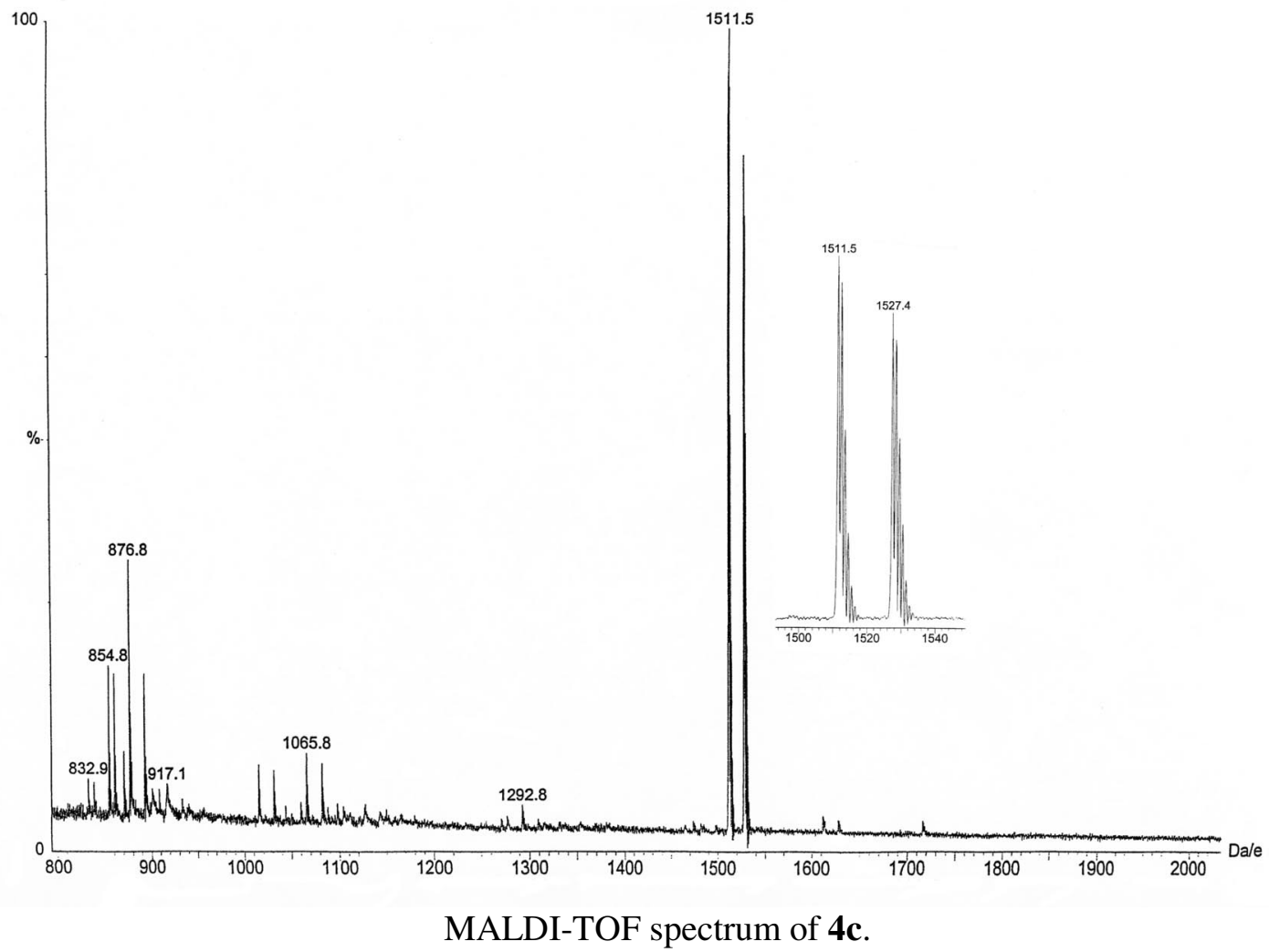




\section{NMR and X-ray structures data}

Table 1. Reference dihedral angles for establishing the rotamers of $\mathrm{C}$ aromatic ring, determined from the molecular structure of compounds $2 \mathrm{a}, 3 \mathrm{a}$ and $4 \mathrm{a}$.

\begin{tabular}{cccc}
\hline Compound & \multicolumn{2}{c}{ Torsion angles } \\
\cline { 1 - 1 } \cline { 3 - 4 } \cline { 3 - 4 } 2a & & $\mathrm{C}$ aromatic ring $/ \mathrm{C}^{12} \mathrm{C}^{13} \mathrm{C}^{34}$ & aromatic ring $/ \mathrm{C}^{9} \mathrm{C}^{8} \mathrm{C}^{33}$ \\
3a & & 90.4 & 91.1 \\
4a & & 84.4 & 89.3 \\
& 75.7 & 111.2 \\
\hline
\end{tabular}

Table 2. Selected ${ }^{1} \mathrm{H}$ NMR data $\left(\mathrm{CDCl}_{3}, \delta\right.$, ppm) for compounds $3_{\mathrm{a}-\mathrm{c}}$ and $\mathbf{4}_{\mathrm{a}-\mathrm{c}}$.

\begin{tabular}{|c|c|c|c|c|c|}
\hline \multirow[t]{2}{*}{ Compound } & \multicolumn{2}{|c|}{ 1,3-dioxane rings } & \multirow[t]{2}{*}{$-\mathrm{CH}_{2}-\mathrm{O}-$} & \multirow{2}{*}{$\begin{array}{l}\mathrm{CH}_{3}(\mathrm{eq}) \\
\text { acetal part }\end{array}$} & \multirow{2}{*}{$\begin{array}{l}\mathrm{CH}_{3} \text { (ax) } \\
\text { alkyl part }\end{array}$} \\
\hline & ax & eq & & & \\
\hline $3 \mathbf{a}$ & 3.99 & 3.47 & 4.08 & 1.53 & 1.35 \\
\hline $\mathbf{3 b}$ & 3.75 & 3.66 & 4.00 & 1.55 & 1.32 \\
\hline $3 c$ & 3.73 & 3.63 & 3.98 & 1.54 & 1.34 \\
\hline $4 \mathbf{a}$ & 3.63 & 3.54 & 4.18 & 1.55 & 1.23 \\
\hline $4 b$ & 3.67 & 3.57 & 3.90 & 1.52 & 1.33 \\
\hline $4 c$ & 3.65 & 3.54 & 3.90 & 1.52 & 1.26 \\
\hline
\end{tabular}




\section{Low temperature COSY spectrum of compound 2a}

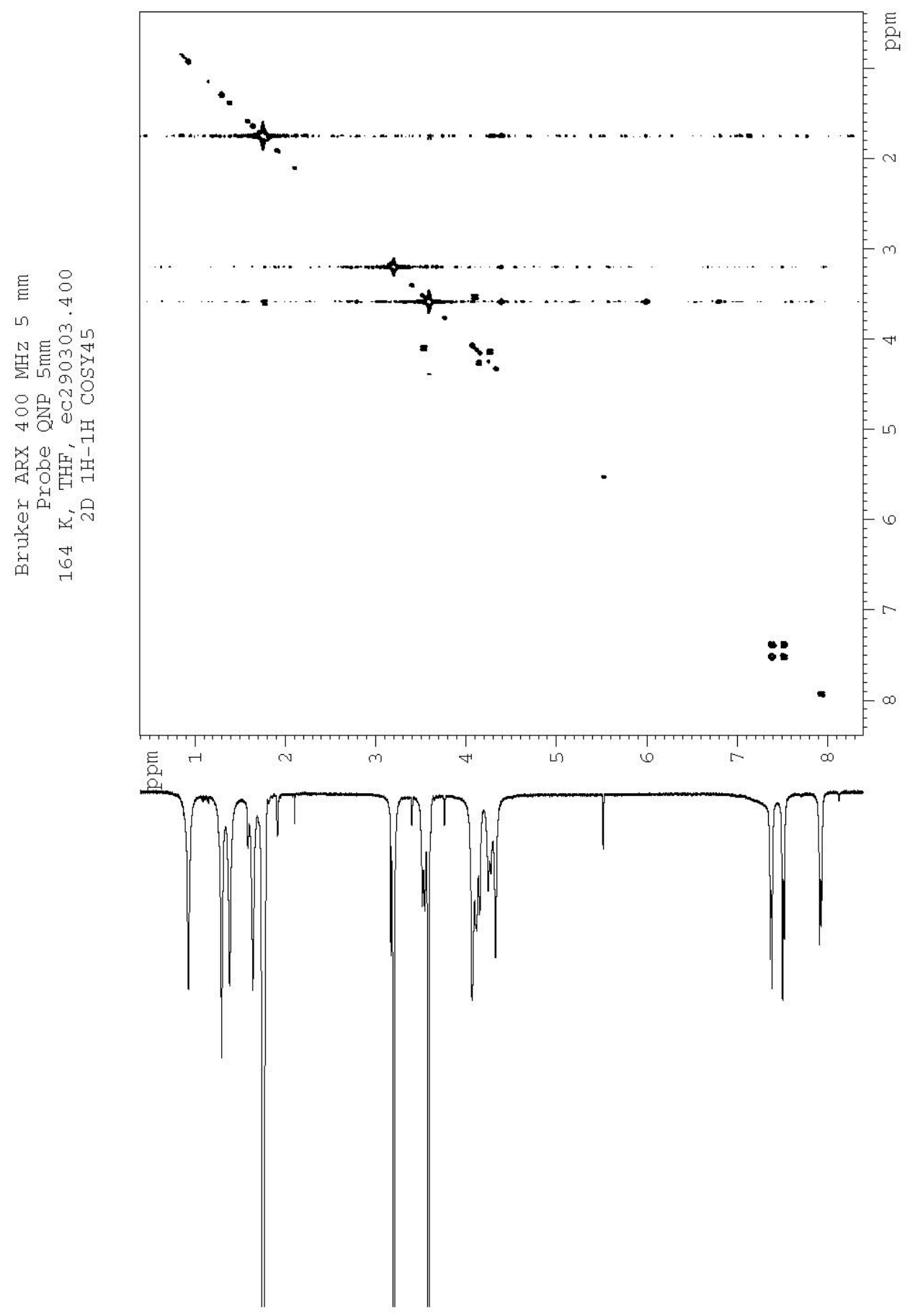


Low temperature NOESY spectrum of compound 2a.

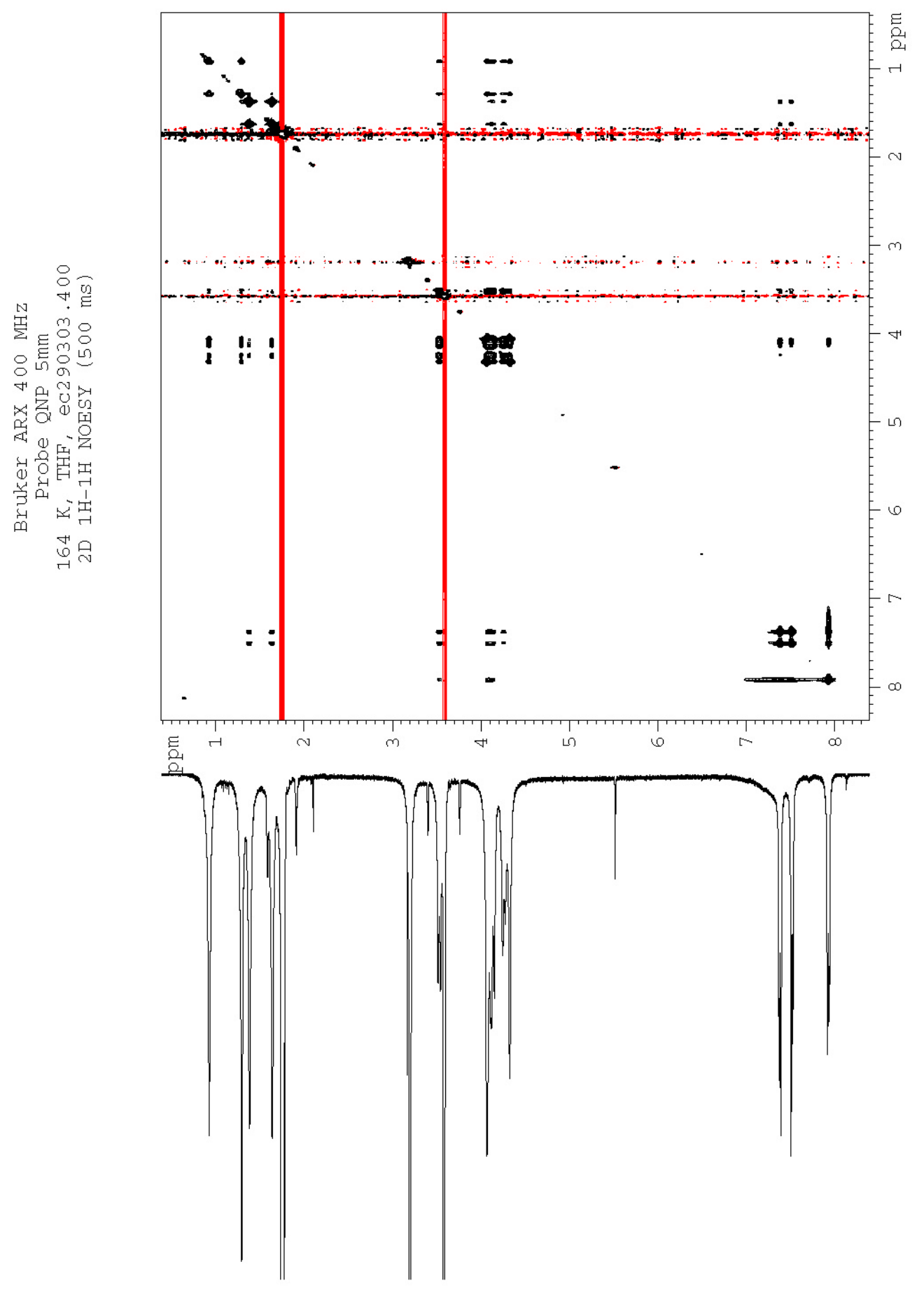




\section{Low temperature ROESY spectrum (fragment) of compound 2a.}

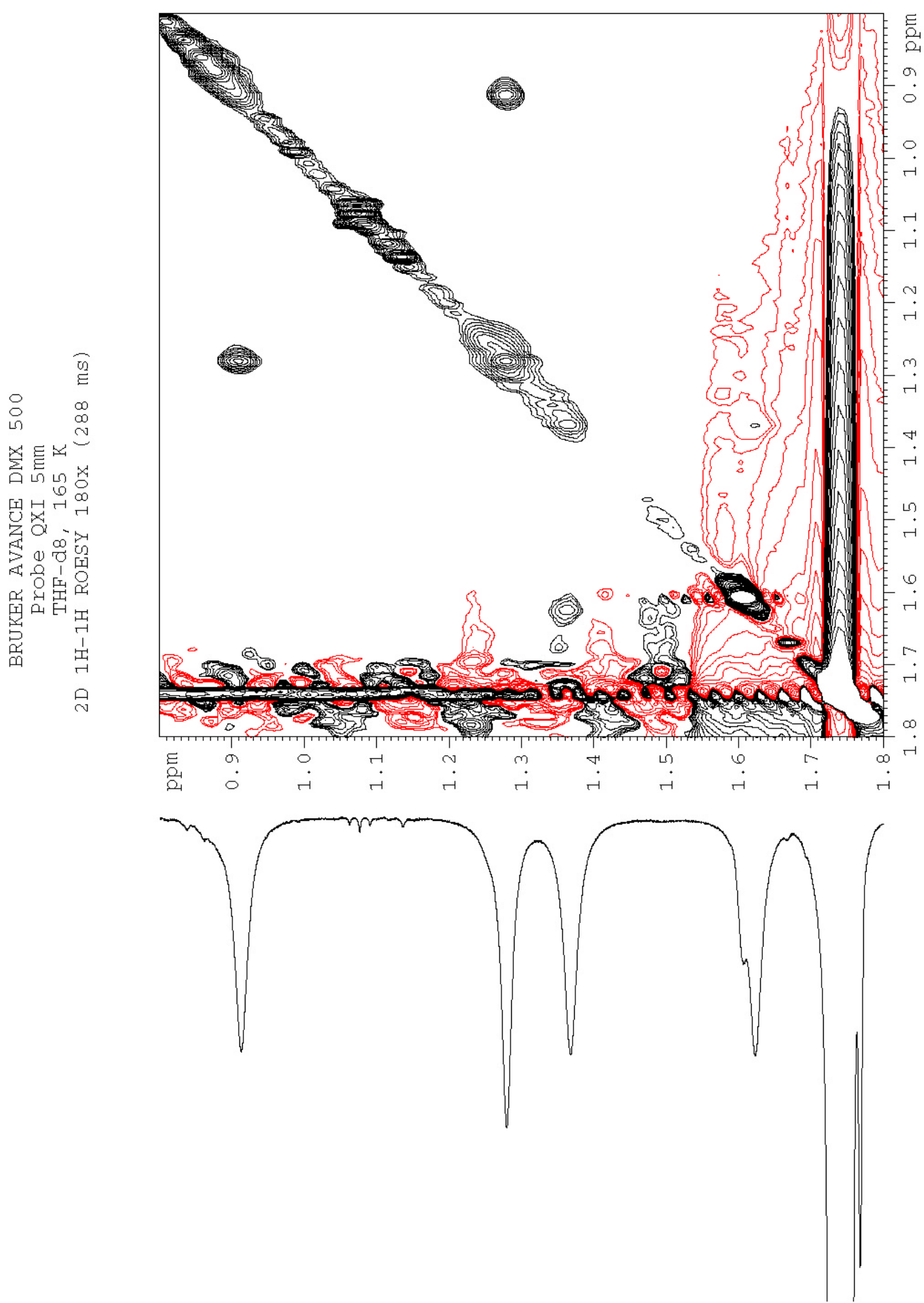




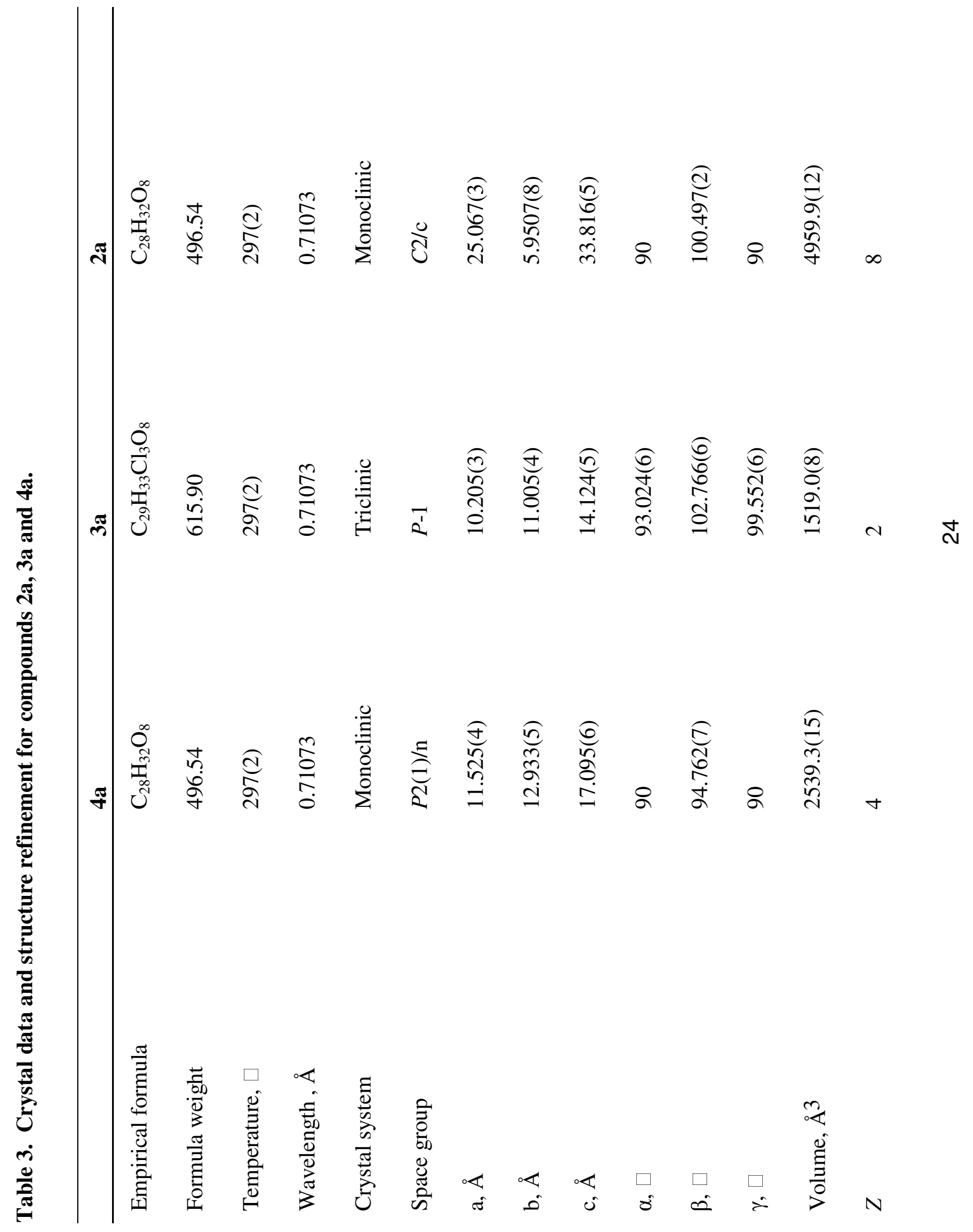




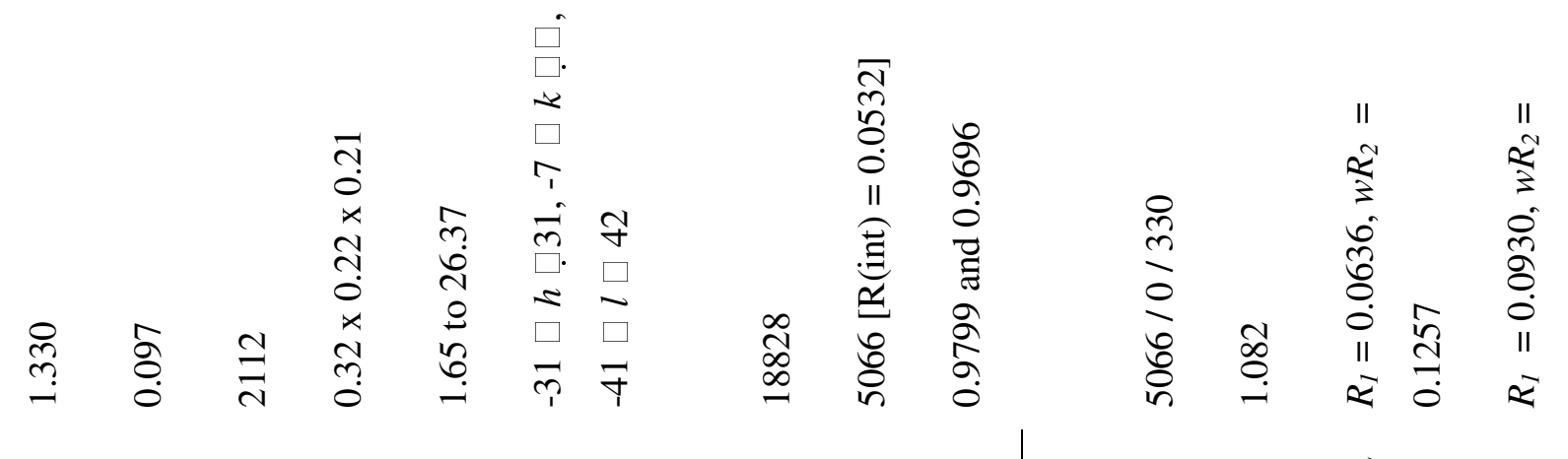

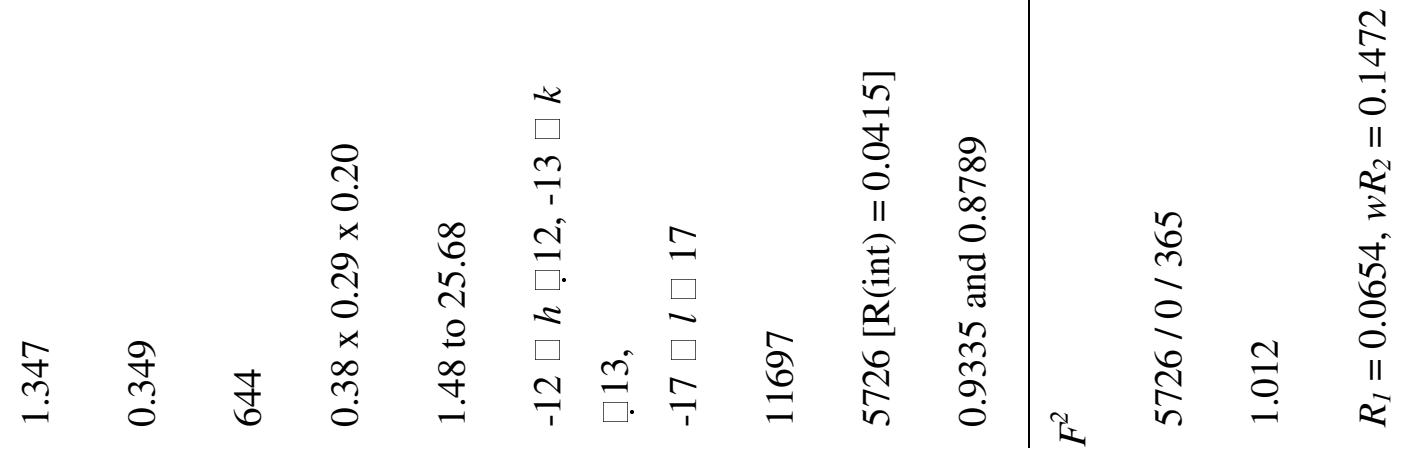

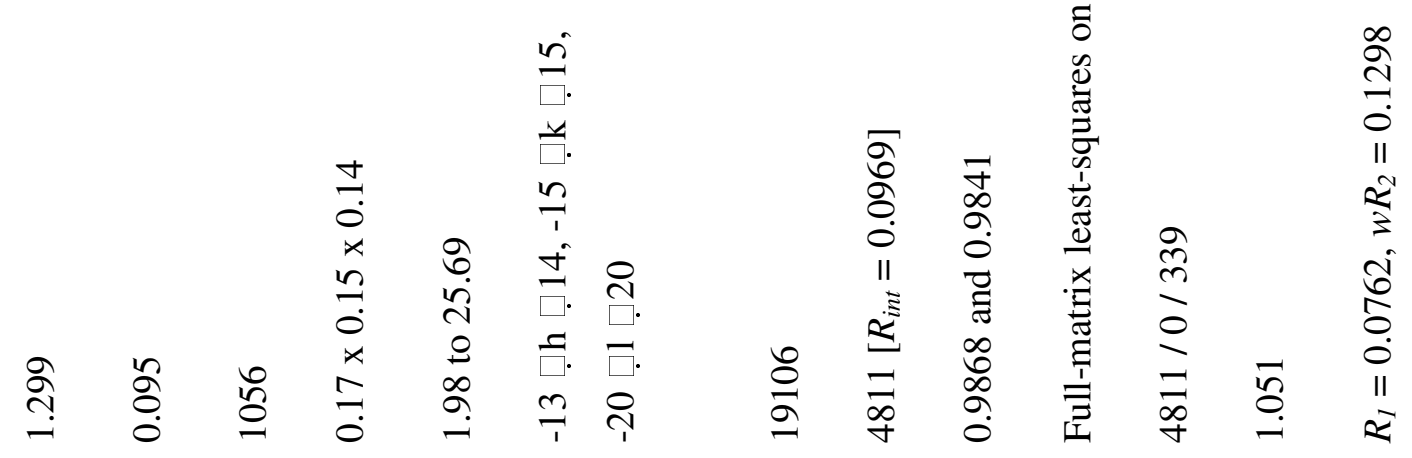

م

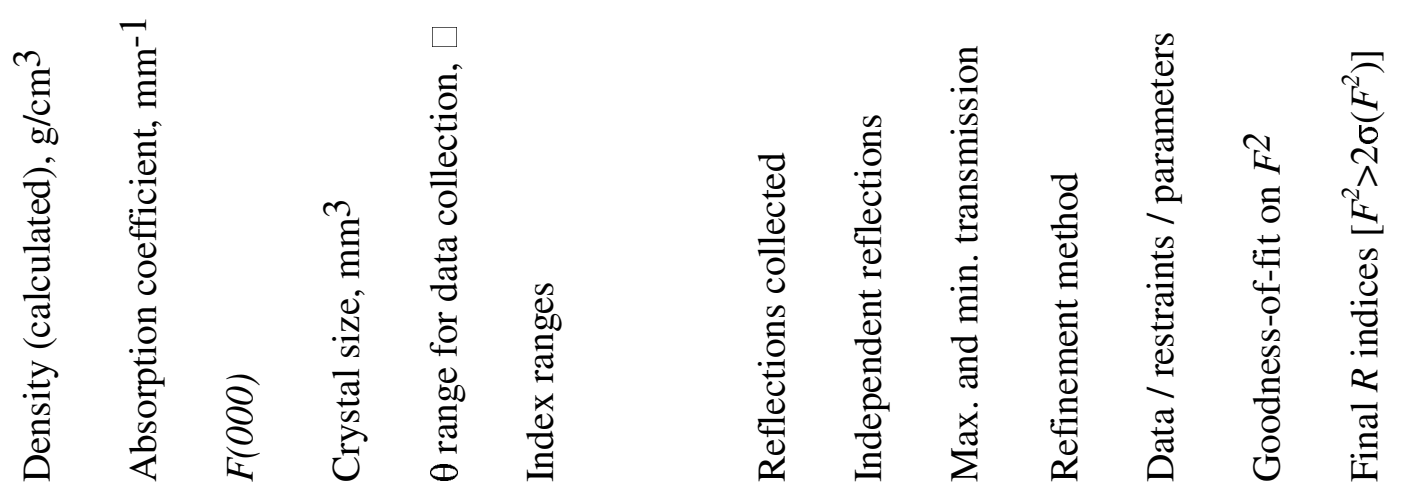




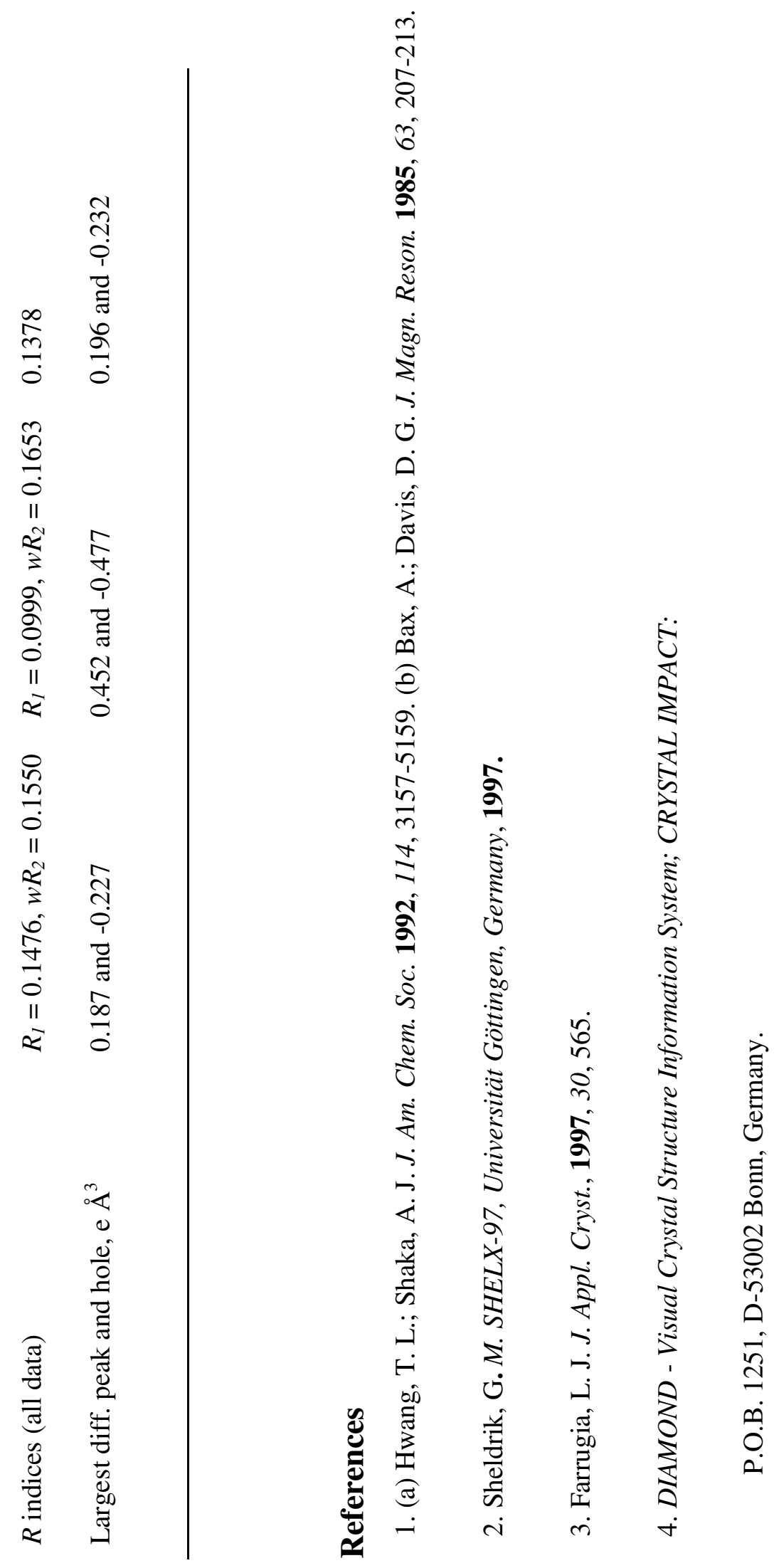

